\title{
Radical-radical rotaxanes with tetracationic cyclophane ring, and quaternary azaaromatic rotaxanes with cage macrocycles
}

\author{
M. Deska, A. Nowik-Zajac, and W. Sliwa* \\ Jan Dlugosz University, Institute of Chemistry, Environmental Protection and Biotechnology, \\ 42-200 Czestochowa, Armii Krajowej 13/15 Street, Poland \\ E-mail:w.sliwa@ajd.czest.pl
}

DOI: $\underline{\text { http://dx.doi.org/10.3998/ark.5550190.0015.100 }}$

\begin{abstract}
The review consists of two parts. In the first part the radical-radical quaternary azaaromatic rotaxanes containing tetracationic cyclophane ring are described, and in the second part rotaxanes built from quaternary azaaromatic threads and cage macrocycles, such as cyclodextrins, calixarenes, pillararenes and cucurbiturils are presented. The species described here are discussed as regards their properties and possible applications.
\end{abstract}

Keywords: Calixarene, cucurbituril, cyclodextrin, pillararene, radical cation, shuttling

\section{Table of Contents}

1. Introduction

2. Radical-radical Rotaxanes Containing Tetracationic Cyclophane as a Ring

2.1. Bistable rotaxanes

2.2. Tristable rotaxanes

3. Quaternary Azaaromatic Rotaxanes Containing Cage Macrocycles as Rings

3.1. Rotaxanes containing identical rings

3.1.1. Cyclodextrin-based rotaxanes

3.1.2. Calixarene-based rotaxanes

3.1.3. Pillararene-based rotaxanes

3.1.4. Cucurbituril-based rotaxanes

3.2. Rotaxanes containing different rings

3.2.1. Cyclodextrin/calixarene-based rotaxane

3.2.2. Cyclodextrin/cucurbituril-based rotaxane

3.2.3. Cyclodextrin/calixarene/cucurbituril-based rotaxane

4. Conclusions 


\section{Acknowledgements}

References

\section{Introduction}

The review is divided into two parts; the first part, a continuation of our former paper, ${ }^{1}$ concerns quaternary azaaromatic rotaxanes containing tetracationic cyclophane ring, which are formed by radical pairing interaction. It should be pointed out that such radical-radical rotaxanes are new species in contrast with traditional donor-acceptor rotaxanes. ${ }^{2,3}$ In this part radical-radical rotaxanes are described, showing their syntheses and properties. The influence of an electrostatic barrier incorporated in their threads is discussed; among the considered compounds also degenerate rotaxanes are presented.

The second part deals with rotaxanes consisting of quaternary azaaromatic thread and cage macrocycles serving as rings; for cage macrocycles cyclodextrins, ${ }^{4}$ calixarenes, ${ }^{5}$ pillararenes ${ }^{6}$ and cucurbiturils ${ }^{7}$ have been chosen. As examples, the rotaxanes containing one or more rings of the same kind, as well as rotaxanes containing different rings are presented, pointing out their application possibilities on various fields. Compounds described in both parts are promising for design of molecular electronic devices, ${ }^{8}$ nonvolatile molecular memories ${ }^{9}$ and switches, ${ }^{10}$ molecular machines, ${ }^{11,12}$ machines of an autonomous character ${ }^{13,14}$ and materials of special properties. $^{15-18}$

One should point out that rotaxanes and pseudorotaxanes, widely investigated species belonging to mechanically interlocked molecules (MIMs) are of interest in construction of memory devices and switches, and in biological applications ${ }^{19-21}$ Attention is paid today to polyrotaxanes, an intensively studied area of chemistry and related sciences, ${ }^{22,23}$ supramolecular polymers are a topic of a wide research due to their self-assembled nature and valuable properties. $^{24-26}$

The present review is a continuation of our former papers on donor-acceptor rotaxanes with tetracationic cyclophane ring, ${ }^{1}$ rotaxanes with threads containing pyridinium ${ }^{27}$ and viologen units, ${ }^{28}$ and of our works concerning quaternary azaaromatics, ${ }^{29,30}$ as well as cyclodextrins ${ }^{31,32}$ and calixarenes. ${ }^{33-35}$

\section{Radical-radical Rotaxanes Containing Tetracationic Cyclophane as a Ring}

In the study of rotaxanes it was found that molecular recognition can be enhanced by radicalradical interaction; this enhanced recognition can be useful in the control of the work of molecular switches and machines.

In degenerate rotaxanes, i.e. those containing two equivalent recognition sites, the ring $\mathbf{W}$ (wheel) shuttles between two sites under the influence of heat. 
In traditional bistable rotaxanes, where donor-acceptor interaction is a recognition motif, two possibilities exist:

a) the ring is the electron deficient $\mathbf{W}^{4+}$ which can be induced to move from e.g. the TTF unit to the DNP by oxidation of TTF to its radical cation $\mathrm{TTF}^{\cdot+}$ or dication $\mathrm{TTF}^{2+}$. Such redox-active systems have been incorporated into nanoelectromechanical switches (NEMs) to form prototypes of memory chips.

b) the ring is an electron rich benzo- or naphtho-crown ether, and the viologen, further referred to as bipyridinium ${ }^{2+}$, i.e. BIPY $^{2+}$ as an electron deficient complementary component is incorporated in the thread (these species are not the theme of the present paper).

In the recently discovered bistable radical-radical rotaxanes where radical-radical interaction is a recognition motif, the two-electron reduced $\mathbf{W}^{4+}$, i.e. bisradical dication $\mathbf{W}^{2(\cdot+)}$ is a ring, and the one-electron reduced $\mathrm{BIPY}^{2+}$, i.e. radical cation $\mathrm{BIPY}^{\circ+}$ is a complementary recognition site in the thread. ${ }^{36}$ One may compare this radical-radical interaction to dimerization (also referred to as pimerization) of $\mathrm{BIPY}^{\cdot+}$ radical cations leading to a dimer, i.e. a pimer $\left(\mathrm{BIPY}^{{ }^{+}}\right)_{2}$ which acts as a guest in neutral hosts, e.g. in cucurbiturils. ${ }^{37}$

First the bistable rotaxanes are described; these are followed by tristable rotaxanes.

\subsection{Bistable rotaxanes}

1) It was established that the BIPY ${ }^{\circ+}$ radical cations form strong inclusion complexes with $\mathbf{W}^{2(\cdot)}$ in its reduced bisradical dicationic state due to radical-pairing, and by radical templation the mechanical bond may be formed. In this process an "unlikely rotaxane" $\mathbf{R} \cdot 6 \mathrm{PF}_{6}$ consisting of two positively charged components, i.e. the thread and the ring was synthesized.

The synthesis of [2] rotaxane $\mathbf{R} \cdot 6 \mathrm{PF}_{6}$ begins with the reaction of $\mathbf{T}^{\mathbf{2}+}$ (thread) containing BIPY ${ }^{2+}$ with $\mathbf{W}^{4+}$ which are reduced by $\mathrm{Ru}(\mathrm{bpy})_{3}{ }^{2+}$ activated by visible light to give pseudo[2] rotaxane $\mathbf{T}^{\cdot+} \cdot \mathbf{W}^{\mathbf{2 ( \cdot + )}}$, in which the ring $\mathbf{W}^{2(\cdot+)}$ encircles the BIPY ${ }^{\bullet+}$ unit of the thread. Triethanolamine, used as a sacrificial electron donor, prevents the back electron transfer from the radical cation $\mathrm{BIPY}^{{ }^{+}}$to $\mathrm{Ru}(\mathrm{bpy}) 3^{3+}$. In this process three $\mathrm{BIPY}^{2+}$ units, i.e. one of the thread and two of the ring undergo reduction to their radical cations BIPY ${ }^{\circ+}$. The formed pseudorotaxane $\mathbf{T}^{\cdot+} \cdot \mathbf{W}^{\mathbf{2}(\cdot)}$ by treatment with di-t-butyl acetylenedicarboxylate for introduction of stoppers via click reaction, affords the rotaxane $\mathbf{R}^{3(\cdot+)}$.

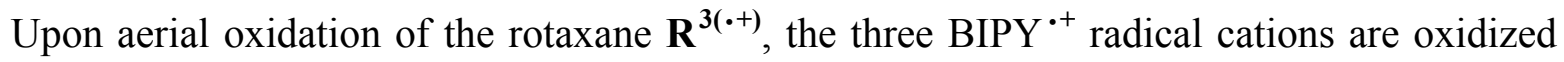
back to BIPY ${ }^{2+}$ units and the rotaxane loses its stability, since Coulombic repulsion appears between the two positively charged components. Therefore this process is accompanied by the shuttle of $\mathbf{W}^{4+}$ away from the BIPY ${ }^{2+}$ unit resulting in the formation of the "unlikely rotaxane" $\mathbf{R} \cdot 6 \mathrm{PF}_{6}$.

These observations indicate that the oligomethylene chain in [2] rotaxane $\mathbf{R} \cdot 6 \mathrm{PF}_{6}$ plays a role of a "pseudo-station" for the ring $\mathbf{W}^{4+}$ although this chain shows no binding affinity to the ring. In order to explain the mechanism of rotaxanation proceeding by radical templation, the electrochemistry and spectroelectrochemistry (SEC) measurements of the [2] rotaxane $\mathbf{R} \cdot 6 \mathrm{PF}_{6}$ were performed. 
Results of electrochemical study of the "unlikely rotaxane" $\mathbf{R}^{6+}$ have shown that its reduction to the trisradical tricationic form $\mathbf{R}^{3(\cdot+)}$ occurs via two different electron-transfer processes. The first one is a two-electron reduction, forming paired BIPY ${ }^{\bullet+}$ radical cations: one of the thread with one of the ring to form the bisradical tetracationic intermediate $\mathbf{R}^{2(\cdot+)(2+)}$. The subsequent process, i.e. the one-electron transfer is a reduction of the remaining unpaired BIPY $^{2+}$ of $\mathbf{W}^{(\cdot+)(2+)}$; as a consequence the trisradical tricationic $\mathbf{R}^{3(\cdot+)}$ is formed.

In the above procedure the "unlikely rotaxane" $\mathbf{R} \cdot 6 \mathrm{PF}_{6}$ comprising only electron-deficient units, i.e. $\mathrm{BIPY}^{2+}$ and $\mathbf{W}^{4+}$, which does not possess any complementary electron-rich components has been synthesized. The interactions of radical dimers have been used as a recognition motif to create a mechanically interlocked system. This combination of templation with radical-pairing is promising for preparation of mechanically interlocked molecules (MIMs) composed of species which have little or no binding affinities in their ground states ${ }^{38}$ (Scheme 1). It should be mentioned that the structures of radical cations given in Scheme 1 and the following are a short way of representing these species; they do not show their valence-bond forms.

2) It is known that the radical-cations BIPY $^{\cdot+}$ show a strong tendency to undergo pimerization, in which two or more BIPY ${ }^{++}$units come together in a face-to-face manner to form $\left(\mathrm{BIPY}^{\cdot+}\right)_{2}$ radical $\pi$-dimers, i.e. pimers. This formation of $\left(\mathrm{BIPY}{ }^{\cdot+}\right)_{2}$ radical dimers, i.e. pimerization is driven mainly by the free energy obtained from the pairing of their unpaired $\pi$-electrons.

To achieve the formation of $\left(\mathrm{BIPY}^{\bullet+}\right)_{2}$ dimers in solution, there should be constructed a cage, referred to as a "molecular flask" ${ }^{39}$ for the enforced association of these radicals. As an example of such "molecular flask" may serve cucurbit[8]uril; when (BIPY $\left.{ }^{\cdot+}\right)_{2}$ is encapsulated in the cavity of $\mathrm{CB} 8$, the stability of this radical dimer is enhanced..$^{9,40}$

It was found that the ring $\mathbf{W}^{2(\cdot+)}$ itself is able to form with BIPY ${ }^{\bullet+}$ unit the stable trisradical tricationic $\mathbf{W}^{2(\cdot+)} \cdot \mathrm{BIPY}^{\bullet+}$ inclusion complex; the ring $\mathbf{W}^{2(\cdot+)}$ offers a preorganized cavity where the BIPY $^{\bullet+}$ guest can undergo efficient $\pi-\pi$ stacking with both BIPY ${ }^{\bullet+}$ units of the $\mathbf{W}^{2(\cdot+)}$ ring. It should be noted that the rotaxanes containing BIPY ${ }^{\bullet+}$ units may be integrated into nanoelectromechanical systems (NEMs). ${ }^{41}$

The radical nature of BIPY $^{\circ+}$ units is promising for design of functional composite materials, useful for conductive molecular electronic devices ${ }^{42}$ or paramagnetic materials. ${ }^{43,44}$ However, an inconvenience for these applications is the low resistance of BIPY ${ }^{\bullet+}$ radical cations to oxidation by atmospheric oxygen. Today the finding of ways to increase the stability of $\mathrm{BIPY}^{\cdot+}$ radical cations toward atmospheric oxygen is in radical chemistry of great importance.

The influence of the mechanically interlocked nature of a homologous series of [2] rotaxanes $\mathbf{R n} \cdot 6 \mathrm{PF}_{6}(\mathrm{n}=3-11)$ on their structural and electronic properties has been investigated ( $\mathrm{n}$ represents the number of the methylene groups on each side of the BIPY ${ }^{2+}$ unit situated in the middle of the thread. ${ }^{8}$ Rotaxanes $\mathbf{R n}$ consist of a ring $\mathbf{W}^{4+}$ encircling the dumbbell which contains central BIPY ${ }^{2+}$ unit serving as an electrostatic "speed bump"; they are "unlikely rotaxanes" built from two positively charged components. 


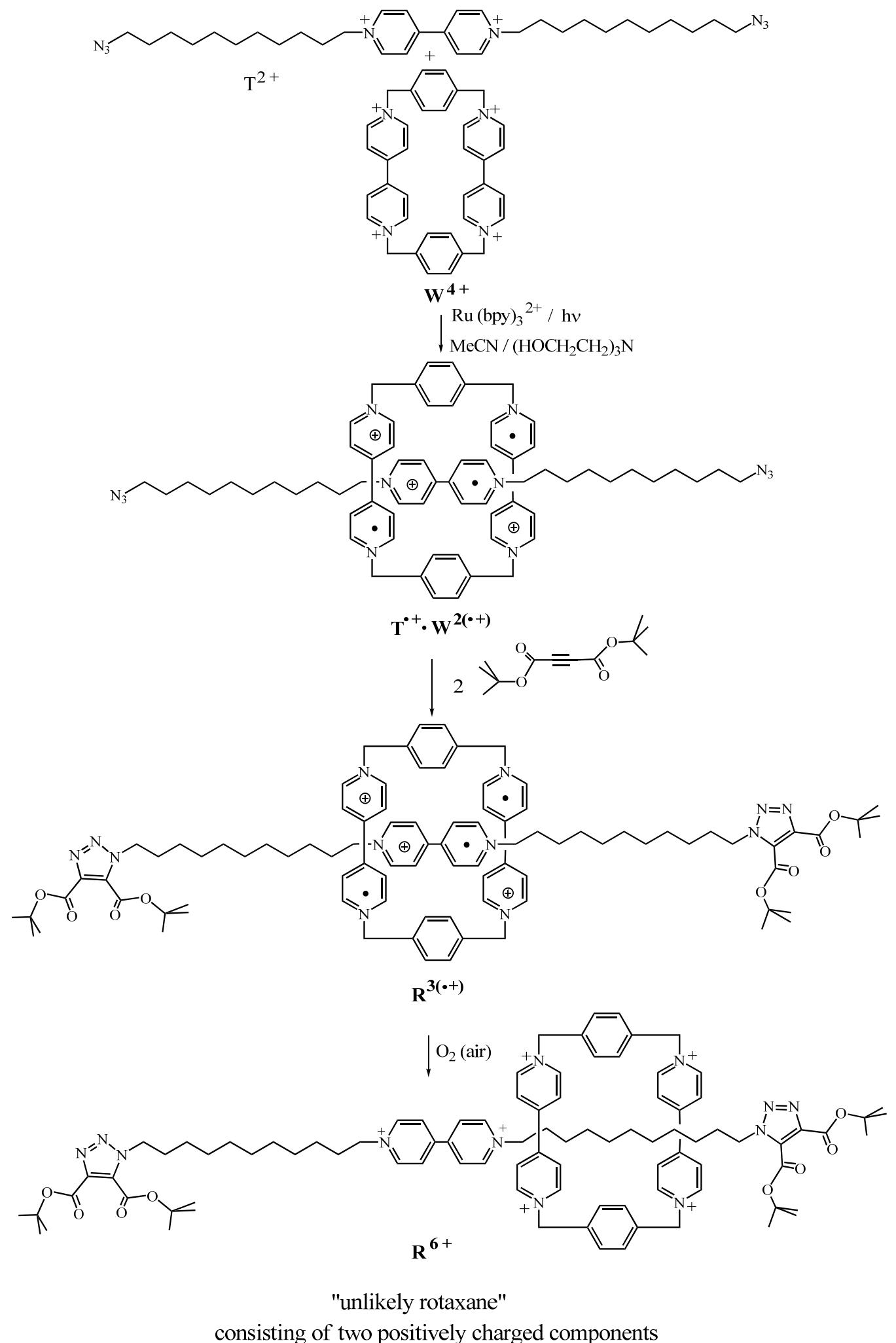

(for clarity the $\mathrm{PF}_{6}^{-}$anions are omitted)

\section{Scheme 1}


Synthesis of rotaxanes $\mathbf{R} 3^{6+}-\mathbf{R}^{6} 1^{6+}$, involving the radical templation, begins with the reaction of threads $\mathbf{V}^{2+}$ with $\mathbf{W}^{4+}$. In order to reduce the BIPY ${ }^{2+}$ units in threads $\mathbf{V}^{2+}$ and $\mathbf{W}^{4+}$ to their radical cations BIPY ${ }^{\bullet+}$, the zinc dust was used. The resulting nine pseudorotaxanes $\mathbf{P}$ in the copper-free click reaction with the stopper precursor $\mathbf{S}$ formed rotaxanes $\mathbf{U}$ which without isolation, under work-up resulting in the oxidation of the BIPY ${ }^{\cdot+}$ units yielded rotaxanes $\mathbf{R} 3 \cdot \mathrm{PF}_{6^{-}}$ $\mathbf{R} 11 \cdot \mathrm{PF}_{6}$. One should note that the copper-free click reaction was used, since the $\mathrm{Cu}(\mathrm{I})$ catalyst may oxidize $\mathrm{BIPY}^{\cdot+}$ to $\mathrm{BIPY}^{2+}$. In these rotaxanes no dethreading was observed during several weeks, even at elevated temperatures; this behavior shows that the stoppers are bulky enough to overcome Coulombic repulsion between $\mathrm{BIPY}^{2+}$ and $\mathbf{W}^{4+}$, in this way preventing the dethreading (Scheme 2).

It was found that the mechanical bonds of rotaxanes $\mathbf{R n}$ enforce the proximity between the mechanically interlocked components in their ground state co-conformations (GSCCs), the Coulombic repulsion is increased, and the ground state co-conformations of the fully oxidized forms of rotaxanes become destabilized; the mechanical bonds decrease the activation energy barriers to the shuttling of the $\mathbf{W}^{4+}$ and enhance the stability of their radical states towards oxidation.

In the fully oxidized states, the ring $\mathbf{W}^{4+}$ in shorter rotaxanes resides in positions that are closer to the $\mathrm{BIPY}^{2+}$ units than in longer rotaxanes and therefore undergoes a stronger Coulombic repulsion. In the consequence, the activation energy barriers for shuttling of shorter [2]rotaxanes are lower. These observations are consistent with DFT (density functional theory) calculations. In the result, the smallest $\mathbf{R} 3^{6+}$ is the only one among the nine rotaxanes $\mathbf{R} \mathbf{3}^{6+}$ $\mathbf{R 1 1}^{6+}$ which exists under ambient conditions in a monoradical state.

To study the influence of the mechanical bond on the stabilities of the BIPY ${ }^{++}$radical cations, the UV/Vis/NIR spectroscopic measurements were performed. The zinc dust was used to reduce $\mathbf{R} 3^{6+}$ to its trisradical state, $\mathbf{R 3}^{3(+)}$. Upon filtering off the excess of zinc dust, the spectrum was characteristic for $\mathrm{BIPY}^{\circ+}$ radical-radical interaction, this observation confirms previous results for rotaxanes and pseudorotaxanes. ${ }^{9,40}$

The oxidation of the shorter rotaxanes from their reduced radical states to their fully oxidized states by atmospheric oxygen proceeds slower than in the case of longer rotaxanes. These results are in agreement with the statement that the mechanical bond stabilizes the radical states of shorter [2] rotaxanes more strongly than in the case of longer rotaxanes, by forcing the $\mathbf{W}^{4+}$ rings to reside in closer proximity to the $\mathrm{BIPY}^{2+}$ units. The stability of the BIPY ${ }^{\circ+}$ radical cations toward atmospheric oxygen increases with the shorter oligomethylene chain, is higher when the oligomethylene chain is short, and in the case of the smallest rotaxane, i.e. $\mathbf{R 3}^{6+}$ the monoradical state is formed. These results are promising for the synthesis of stable organic radicals by employing the presence of mechanical bonds. 

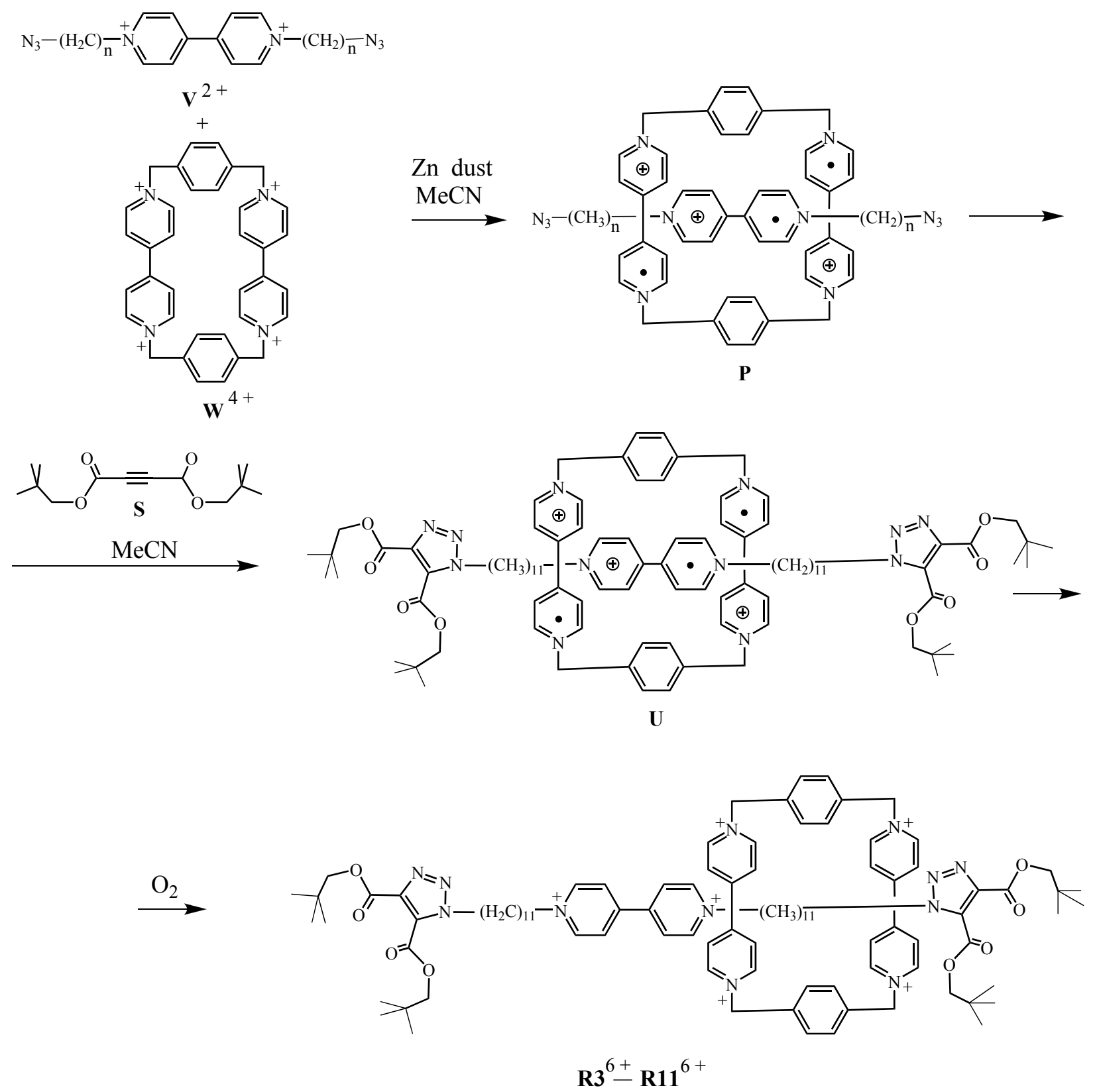

"unlikely rotaxanes"

\section{Scheme 2}

Rotaxanes $\mathbf{R}^{\prime} \mathbf{3}^{\mathbf{6}^{+}}$and $\mathbf{R}^{\prime} \mathbf{1 1}{ }^{6+}$ were also investigated; they have smaller stoppers (containing t-butyl units) than R3 and R11 which have bulkier stoppers (containing 2,2'-dimethylpropyl units). It was found that $\mathbf{R}^{\prime} \mathbf{3}^{6+}$ undergoes decomposition, i.e. dethreading into the free dumbbell and the ring $\mathbf{W}^{4+}$ at room temperature due to the Coulombic repulsion between its two positively charged components. However, $\mathbf{R}^{\prime} \mathbf{1} 1^{6+}$ under these conditions does not dissociate. This different behavior of $\mathbf{R}^{\prime} \mathbf{3}^{6+}$ and $\mathbf{R}^{\prime} \mathbf{1} 1^{6+}$ results from the fact that in $\mathbf{R}^{\prime} \mathbf{3}^{6+}$ the enforced proximity between 
BIPY $^{2+}$ unit and $\mathbf{W}^{4+}$ ring is greatly enhanced compared to that of $\mathbf{R}^{\prime} \mathbf{1 1}{ }^{6+}$ since in $\mathbf{R}^{\prime} \mathbf{3}^{6+}$ the distance between BIPY $^{2+}$ and $\mathbf{W}^{4+}$ is shorter than that in $\mathbf{R}^{\prime} \mathbf{1 1}{ }^{6+}$. Therefore in $\mathbf{R}^{\prime} \mathbf{3}^{6+}$ the Coulombic repulsion is stronger than in $\mathbf{R}^{\prime} \mathbf{1 1}{ }^{6+}$, and is able to activate the dethreading, i.e. the energy barrier for dethreading is decreased and destabilization of the GSCC occurs (Scheme 3).

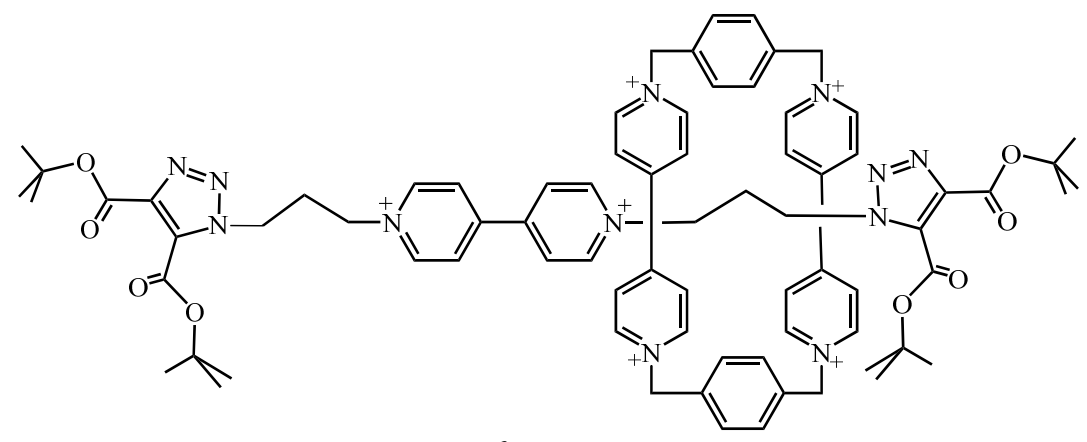

$R^{\prime} 3^{6+}$

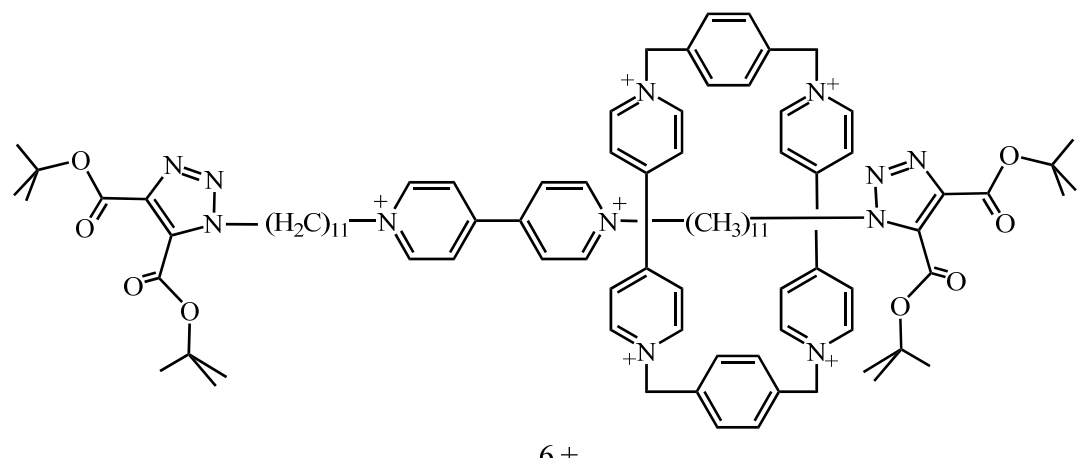

$\mathbf{R}^{\prime} 11^{6+}$

\section{Scheme 3}

The influence of the presence of mechanical bonds on radical stabilization may be illustrated as follows: The solutions of seven [2]rotaxanes, R3-R9 upon reduction with zinc dust turned purple; this indicates formation of trisradical tricationic states. After exposure to air, the purple color of these solutions began to diminish, and it was observed that the color of solutions of the reduced shorter rotaxanes diminished slower than in the case of the longer ones. ${ }^{8}$

The above presented results offer a new possibility to produce highly stabilized BIPY ${ }^{\bullet+}$ radical cations and allow to use stable organic radicals for construction of conductive molecular electronic devices and paramagnetic materials.

3) It was observed that formation of mechanical bonds in the synthesis of [2]rotaxanes may be templated by a radically stabilized trisradical tricationic inclusion complex. ${ }^{2,11,36,38}$ For elucidation of this process, the use of the 1,1-dialkyl-4,4'-bipyridinium radical cationic BIPY ${ }^{\bullet+}$ guests to form inclusion complexes with the diradical dicationic ring $\mathbf{W}^{2(+)}$ has been investigated; as BIPY ${ }^{\bullet+}$ guests served methyl viologen $\mathbf{M V}^{\bullet^{++}}$and dibutynylbis(pyridinium) $\mathbf{V}^{\bullet+}$ 
radical cation. It was established that upon a three-electron reduction of an equimolar mixture of $\mathbf{M V}{ }^{2+}$ and $\mathbf{W}^{4+}$, the $\mathbf{M V}{ }^{*+}$ radical cation is included inside the cavity of $\mathbf{W}^{2(+)}$ bisradical dication; the formed trisradical tricationic complex upon reoxidation regenerates initial $\mathbf{M V}^{2+}$ guest and $\mathbf{W}^{4+}$ host (Scheme 4).<smiles></smiles>

$\mathrm{MV}^{2+}$
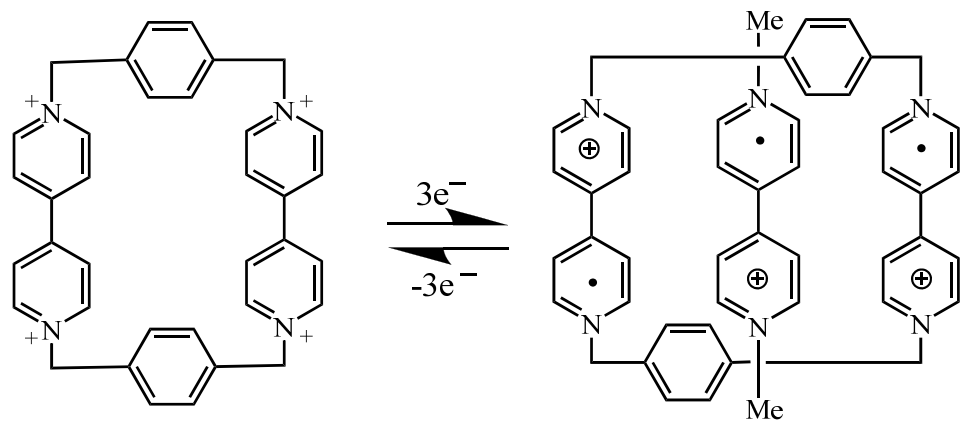

$\mathrm{W}^{4+}$

$\mathrm{MV}^{\bullet+} \cdot \mathrm{W}^{2(\bullet+)}$

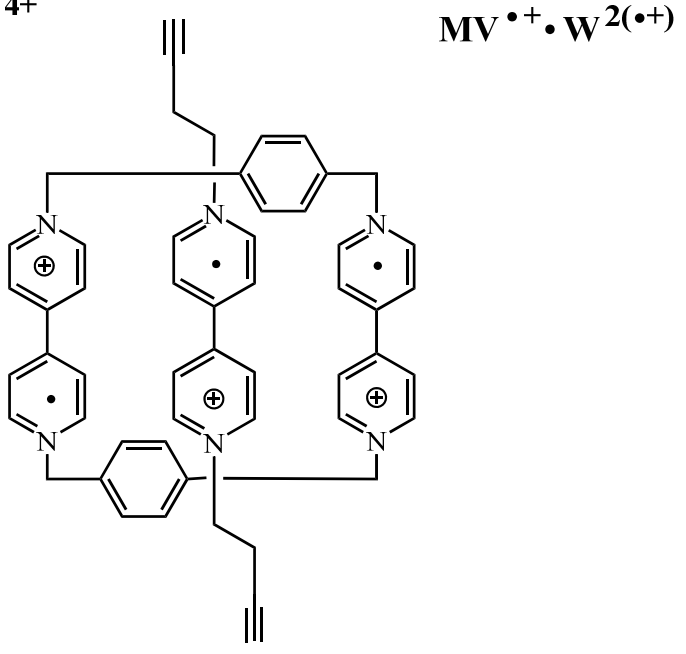

$$
\mathbf{V}^{\bullet+} \cdot \mathbf{W}^{2(\bullet+)}
$$

\section{Scheme 4}

In the experiments the two trisradical tricationic complexes, namely $\mathbf{M V} \mathbf{V}^{\bullet+} \mathbf{W}^{2(+)}$ and $\mathbf{V}^{\bullet+} \cdot \mathbf{W}^{2(+)}$ were formed. In these complexes the guests are situated inside the cavity of $\mathbf{W}^{2(+)}$ centrosymmetrically and the formed 1:1 complexes pack in continuous radical cation stacks. ${ }^{40}$

4) The mechanically induced intramolecular electron transfer (IET) was studied using the [2]rotaxane $\mathbf{K}^{6+}$. The bistable [2] rotaxane $\mathbf{K}^{6+}$ consisting of a dumbbell containing an electron rich DNP unit and an electron-deficient phenylene-bridged bipyridinium (P-BIPY ${ }^{2+}$ ) unit, and having $\mathbf{W}^{4+}$ as a ring exists in the ground state co-conformation (GSCC) when $\mathbf{W}^{4+}$ encircles the DNP unit; it is donor-acceptor interaction.

The rotaxane $\mathbf{K}^{6+}$ upon the two-electron reduction of $\mathbf{W}^{4+}$ forms rotaxane $\mathbf{K}^{2(\cdot+) 2+}$; the formed ring $\mathbf{W}^{2(+)}$ of this rotaxane, due to shuttling begins to move along the dumbbell to the P$\mathrm{BIPY}^{2+}$ unit. The subsequent one-electron reduction of $\mathrm{P}^{-\mathrm{BIPY}^{2+}}$ to the radical cation P-BIPY ${ }^{\circ+}$ 
leads to the formation of rotaxane $\mathbf{K}^{3(\cdot+)}$ existing in the radical state co-conformation (RSCC), it is radical-radical interaction; this shuttling induces IET between the pyridinium redox centers in the P-BIPY ${ }^{+}$unit. It was shown that the above bistable [2] rotaxane is able to switch IET on and off in the $\mathrm{P}-\mathrm{BIPY}^{\bullet+}$ unit through noncovalent binding interactions resulting from encircling of P-BIPY ${ }^{\bullet+}$ by the $\mathbf{W}^{2(\bullet+)}$ ring (Scheme 5).
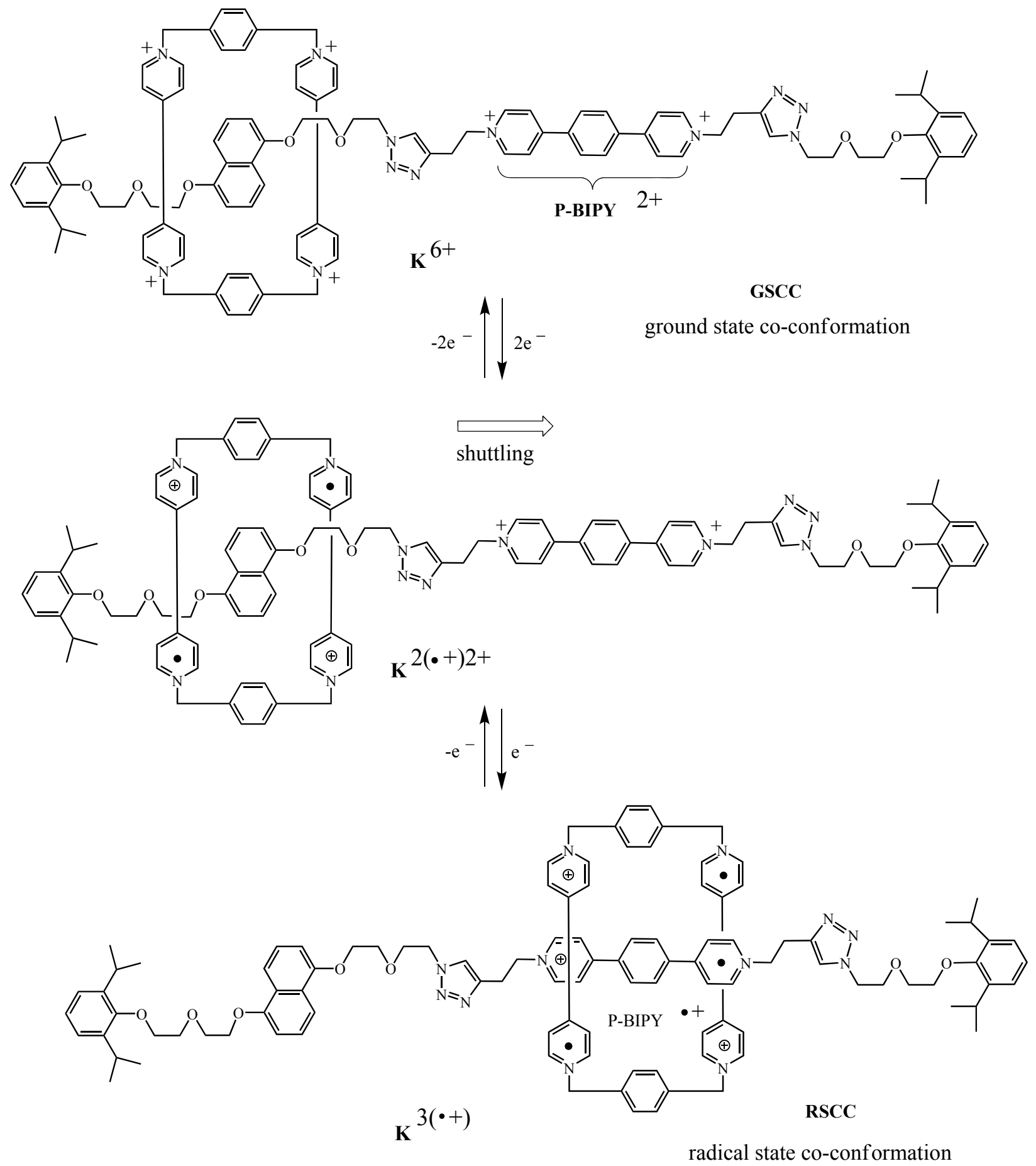

Scheme 5 
The switching of the shuttle, and consequently the enforced noncovalent binding interactions between $\mathrm{P}-\mathrm{BIPY}{ }^{\cdot+}$ and $\mathbf{W}^{2(+)}$ ring in this rotaxane were confirmed by SEC (spectroelectrochemistry) analyses. The IET was studied by EPR spectroscopy and the determined rate constant along with activation energy values were compared to corresponding values predicted by using optical absorption spectra and Marcus-Hush theory; a good compatibility of these comparisons was obtained. ${ }^{45}$

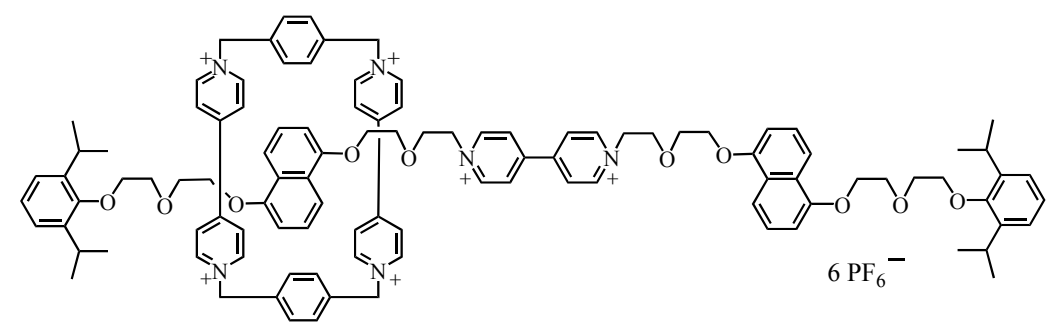

$1 \cdot 6 \mathrm{PF}_{6}$
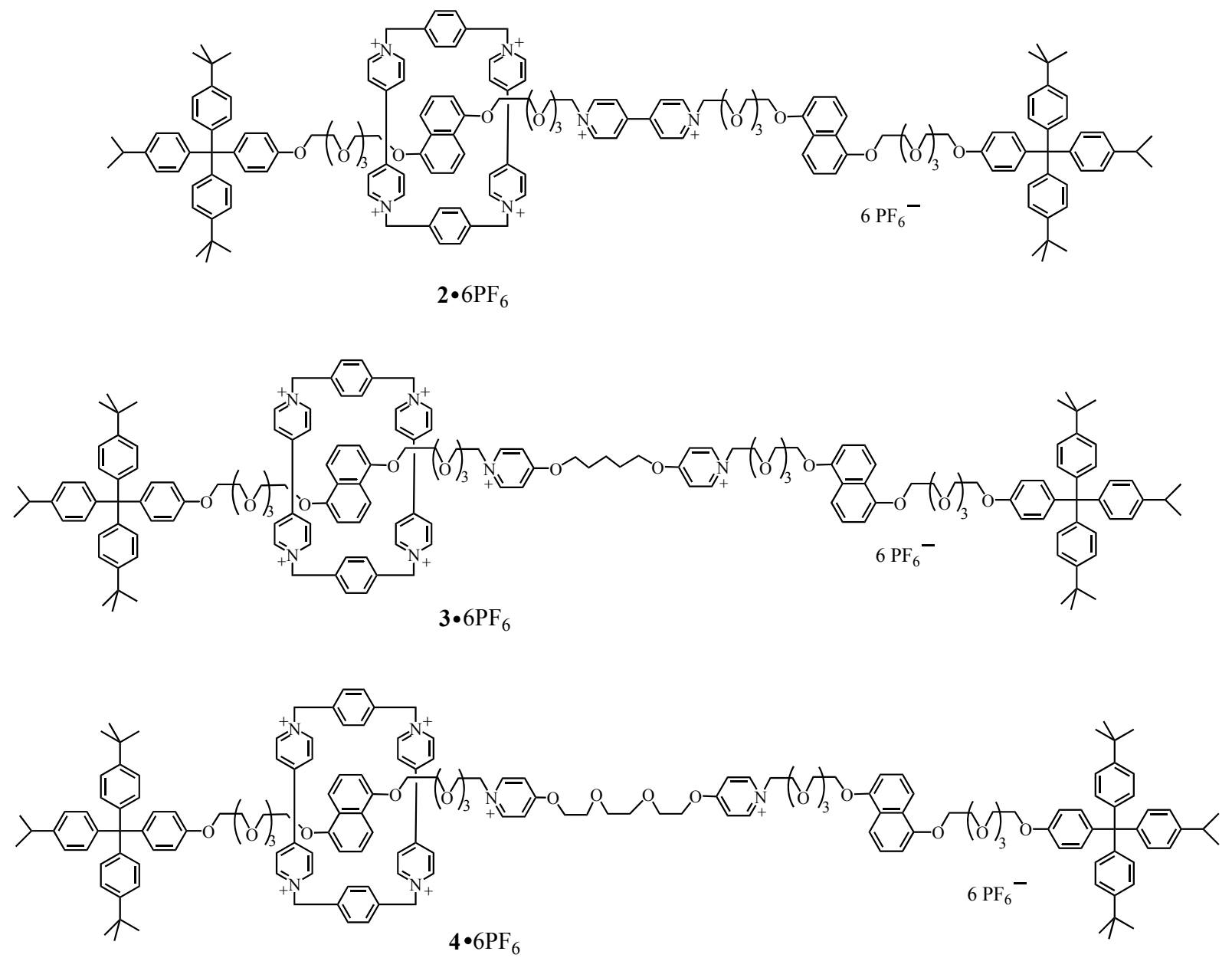

\section{Scheme 6}


5) To better understand the influence of positively charged "speed bumps" situated between two DNP units in degenerate [2]rotaxanes, the rotaxanes 1-4 have been investigated. In 1 and 2 the "speed bumps" are the BIPY ${ }^{2+}$ units; in $\mathbf{3}$ and $\mathbf{4}$, however, because of the presence of the saturated chains, the conjugation between the two pyridinium rings does not exist.

Due to the introduction of the electron-deficient BIPY ${ }^{2+}$ unit into the thread, there appears a Coulombic repulsion between BIPY $^{2+}$ unit and $\mathbf{W}^{4+}$; the rings $\mathbf{W}^{4+}$ in the degenerate [2]rotaxanes undergo only a slow shuttling between two DNP stations. Upon reduction, the BIPY $^{\cdot+}$ and $\mathbf{W}^{2(\cdot+)}$ are formed; BIPY ${ }^{\bullet+}$ serves as an additional recognition site for $\mathbf{W}^{2(\cdot+)}$, and the shuttling of $\mathbf{W}^{2(\cdot+)}$ along the recognition sites, i.e. two DNP units and BIPY ${ }^{\bullet+}$ is induced (Scheme $6)$.

The CV measurements revealed that upon the three-electron reduction of $\mathbf{1}$ and $\mathbf{2}$ the two electrons are gained by $\mathbf{W}^{4+}$, while the third electron is taken up by the BIPY ${ }^{2+}$ unit of the thread. These three-electron reductions result in the encirclement of $\mathbf{W}^{2(\cdot+)}$ around the BIPY ${ }^{\cdot+}$ unit due to radical pairing. As an example the three-electron reduction of $1 \cdot 6 \mathrm{PF}_{6}$, leading to rotaxane $1 \mathrm{a} \cdot 6 \mathrm{PF}_{6}$ is shown (Scheme 7).

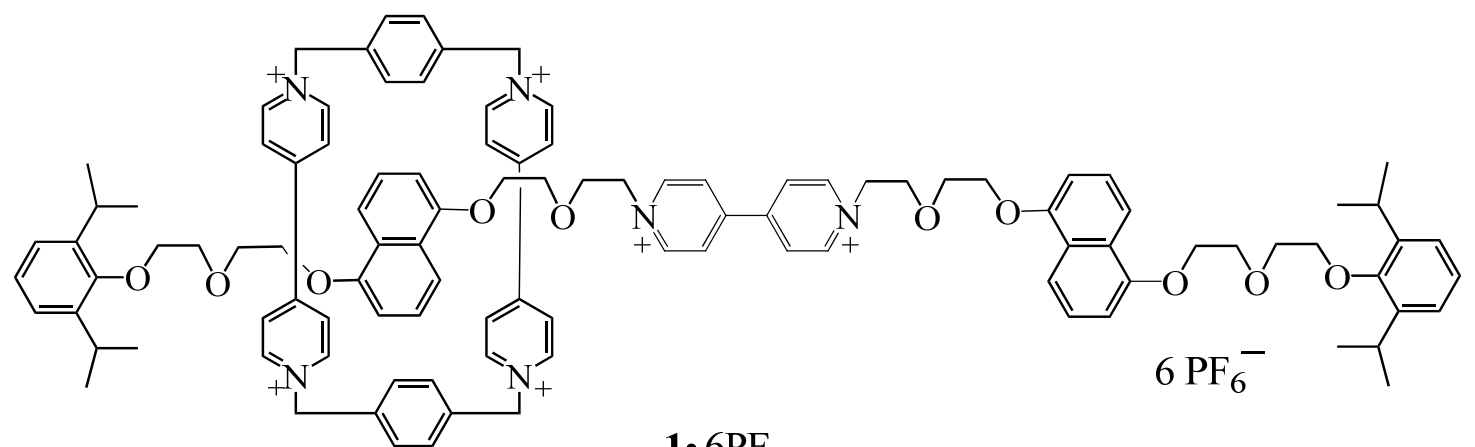

$1 \cdot 6 \mathrm{PF}_{6}$

$-3 e^{-} \mid, 3 e^{-}$

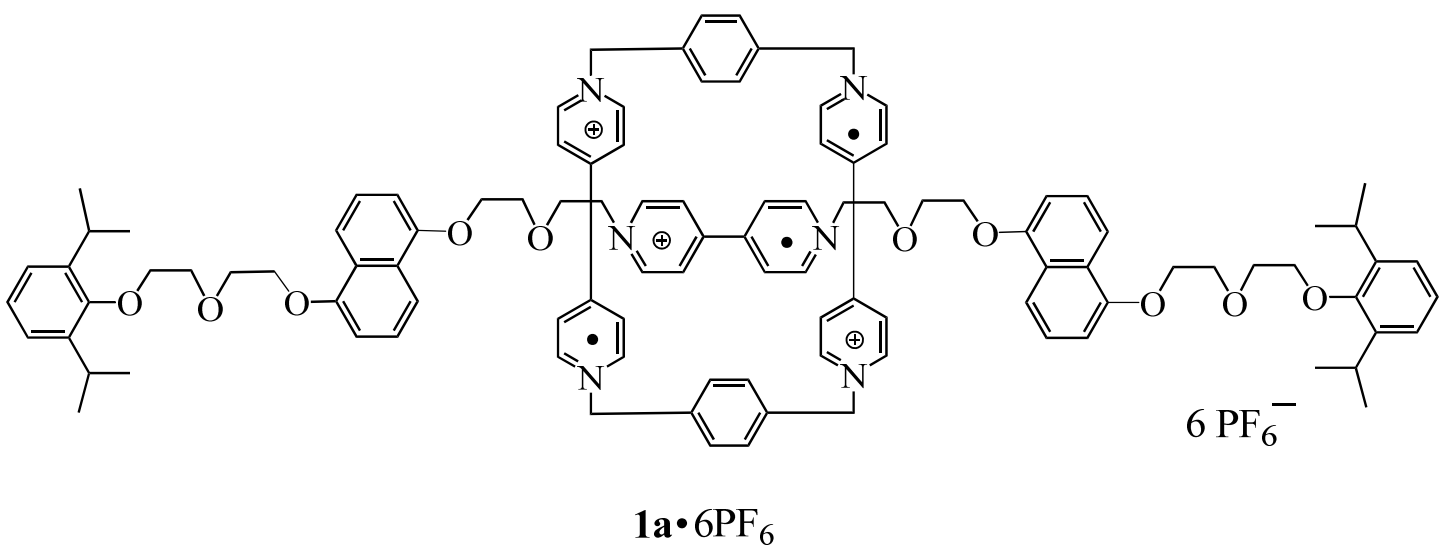

\section{Scheme 7}


The above observations indicate that in degenerate donor-acceptor rotaxanes, the incorporation into the thread of a positively charged unit, e.g. BIPY ${ }^{2+}$ which can be easily reduced, creates the electrostatic barrier to the shuttling of $\mathbf{W}^{4+}$. However, reduction leads to BIPY $^{\bullet+}$ and $\mathbf{W}^{2(\cdot+)}$, which interact by radical pairing. This interaction results in a strong stabilization of the rotaxane, it removes the electrostatic barrier for shuttling and renders the [2]rotaxanes bistable. ${ }^{46}$

In $\mathbf{4}$ and 5, however, no such interactions as in $\mathbf{1}$ and $\mathbf{2}$ were observed; the ring $\mathbf{W}^{4+}$ cannot be induced to shuttle between two DNP units of the dumbbell, since the two pyridinium units are not conjugated and therefore cannot generate radical cations for a pairing with bisradical dication $\mathbf{W}^{2(\cdot+)}$

\subsection{Tristable rotaxanes}

1) Three donor-acceptor [2]rotaxanes, namely two bistable rotaxanes $\mathbf{5}^{6+}$ and $\mathbf{6}^{6+}$ and one tristable rotaxane $7^{6+}$ have been investigated. They have the ring $\mathbf{W}^{4+}$, and the thread containing BIPY $^{2+}$ unit; in the thread may be present DNP (in rotaxane $5^{6+}$ ) or TTF (in rotaxane $6^{6+}$ ) or both DNP and TTF (in rotaxane $7^{6+}$ ). Rotaxanes were obtained using template-directed synthesis enabled by DNP/TTF-W ${ }^{4+}$ molecular recognition, followed by alkyne-azide click reaction for stoppering. It was reported that [2] rotaxanes $5^{6+}-7^{6+}$ can be switched by altering electrochemical potentials.

The three above rotaxanes contain in the thread the BIPY ${ }^{2+}$ unit, which upon reduction acts as a recognition site. In both $\mathbf{5}^{6+}$ and $\mathbf{6}^{6+}$, due to the electrostatic repulsion between BIPY ${ }^{2+}$ and $\mathbf{W}^{4+}$, the ring $\mathbf{W}^{4+}$ is localized exclusively on the DNP unit and on the TTF unit, respectively. Rotaxanes $5^{6+}$ and $\mathbf{6}^{6+}$ can be switched under reductive conditions, making them bistable.

The rotaxane $7^{6+}$ can be switched under both oxidative and reductive conditions. Upon oxidation of this system, TTF affords the radical cation $\mathrm{TTF}^{\cdot+}$ or dication $\mathrm{TTF}^{2+}$, and therefore the ring moves from $\mathrm{TTF}^{\circ+}$ or $\mathrm{TTF}^{2+}$ to DNP unit, while upon reduction BIPY ${ }^{2+}$ becomes the bipyridinium radical cation BIPY ${ }^{\bullet+}$ and the ring $\mathbf{W}^{4+}$ is converted into bisradical dication $\mathbf{W}^{2(\bullet+)}$; in the result BIPY ${ }^{2+}$ forms with $\mathbf{W}^{2(+)}$ an extremely strong complex. This switching of rotaxane $7^{6+}$ under both oxidative and reductive conditions, makes it tristable (Scheme 8).

Rotaxane $7^{6+}$ contains one electron-deficient BIPY ${ }^{2+}$ unit, and two electron-rich units, DNP and TTF. These three recognition units can direct $\mathbf{W}^{4+}$ differently, when the voltage: is negative-to BIPY ${ }^{\cdot+}$; is zero-to TTF; or is positive - to DNP. Therefore, oxidation of TTF results in a very strong repulsion of $\mathbf{W}^{4+}$, causing it to pass over BIPY ${ }^{2+}$ and encircle the DNP unit.

Reduction of both thread and $\mathbf{W}^{4+}$ components generates a three-way molecular switch. This involves the binding of the thread BIPY $^{\bullet+}$ to the ring bisradical dication $\mathbf{W}^{2\left({ }^{++}\right)}$. Consequently, the above redox-active tristable molecular switch, capable to a direct and easily reversible control on reduction and on oxidation is promising for development of molecular electronic devices; one should point out that in the case of only bistable molecular switches such use would be impossible. ${ }^{36}$ 

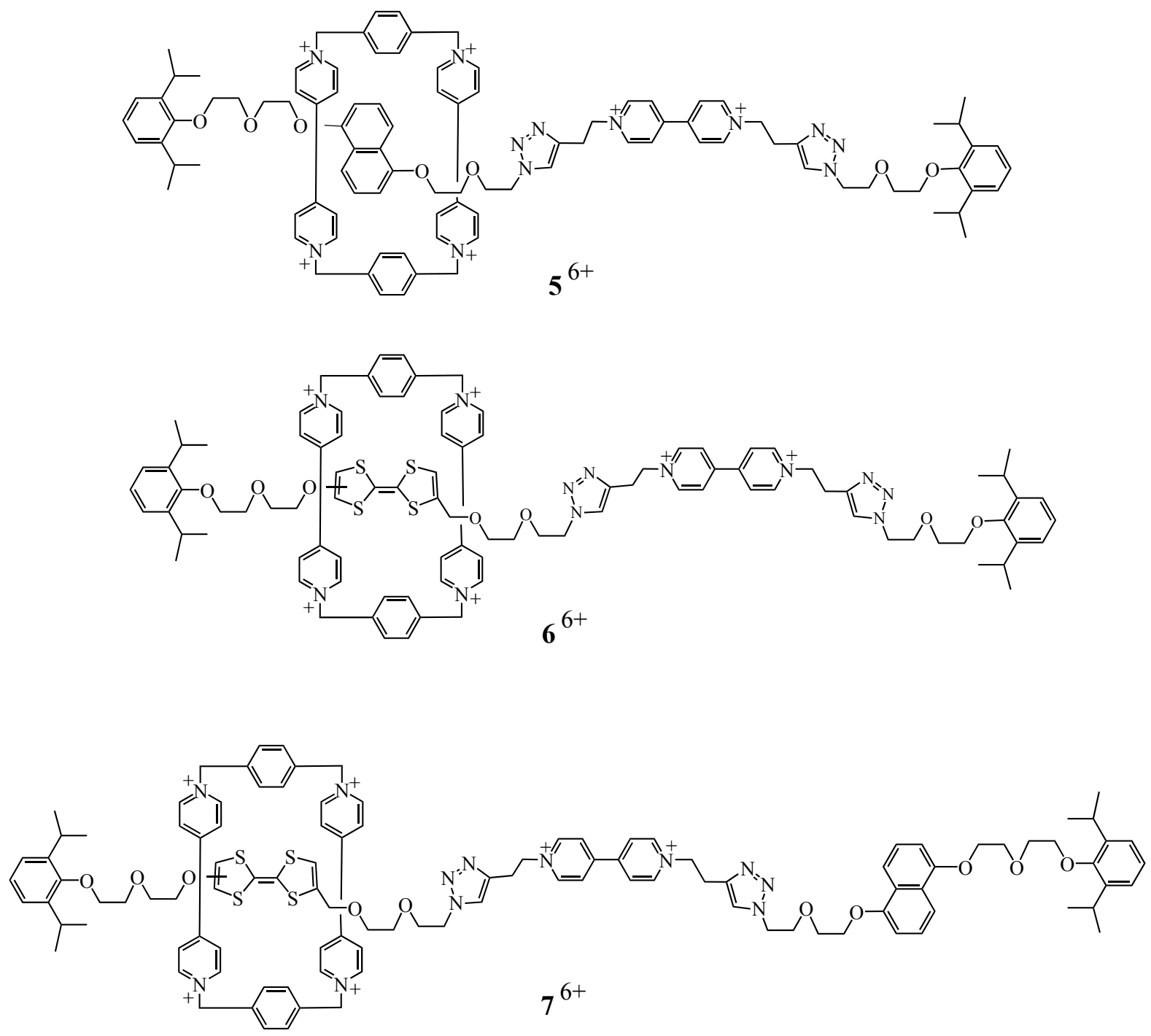

\section{Scheme 8}

2) In the study of radically enhanced molecular switches, the mechanism governing the redox-stimulated switching of $7^{6+}$ was investigated. The BIPY ${ }^{2+}$ unit acts to increase the lifetime of the metastable state co-conformation (MSCC) by restricting the shuttling of the ring $\mathbf{W}^{4+}$ to such extent that the MSCC can be isolated in solid state and is stable for weeks. The mechanism involves a bisradical state co-conformation (BRCC) in which only one of the BIPY ${ }^{\circ+}$ units in the $\mathbf{W}^{2(+)}$ is oxidized to the BIPY ${ }^{2+}$ dication.

In the bistable [2] rotaxanes (consisting of $\mathbf{W}^{4+}$, DNP and TTF) incorporated into memory devices, the ring $\mathbf{W}^{4+}$ encircles the TTF unit in the ground state at equilibrium; this translational isomer is the ground state co-conformation (GSCC). The ring can be forced to encircle the DNP unit, as a result of an oxidation/reduction cycle of TTF, to form a translational isomer, i.e. the metastable-state co-conformation (MSCC). 
The MSCC represents a higher conductive state than the GSCC, therefore MSCC was exploited to achieve single bits of memory in the context of the device. However, the memory implanted in these devices is volatile, and lasts only for about an hour, this behavior is presumably due to the fact that the relaxation of the MSCC back to the GSCC also occurs after about an hour. In view of this hypothesis the increase of the lifetime of the MSCC would allow the construction of nonvolatile molecular memory devices.

In order to increase the lifetime of MSCC, the kinetic barriers may be inserted between TTF and DNP units; they slow down the shuttling of $\mathbf{W}^{4+}$, trapping the MSCC kinetically. To such kinetic barriers or "speed bumps" belong steric barriers, e.g. trans-azobenzene units" or foldamers. $^{48}$

Another method is the use of electrostatic barriers, such as BIPY ${ }^{2+}$ units, which, due to Coulombic repulsion of $\mathbf{W}^{4+}$ may increase the lifetime of MSCC. If the MSCC is trapped, it is necessary to release it in a timely manner, this would allow for the development of bistable rotaxane-based molecular flash memory.

The mechanistic investigation of the redox-active switching of tristable rotaxane $7^{6+}$ consisting of $\mathbf{W}^{4+}$ and the dumbbell containing BIPY ${ }^{2+}$, TTF and DNP units was performed; for comparison purposes also $5^{6+}$ and $\mathbf{6}^{6+}$, in which either TTF or DNP is absent, respectively, were also studied. It was found that BIPY ${ }^{2+}$ unit in $7^{6+}$ serves as so effective electrostatic barrier, that the trapping and isolation of MSCC as a pure solid is possible. For this purpose there was applied the reduction-induced switching, that uses the favorable radical-radical interactions ${ }^{40}$ which occur between BIPY $^{\bullet+}$ radical cations present in the ring and in the thread. It was shown also that the dynamic nature of these radical-radical interactions may be employed to restore the GSCC from the kinetically trapped MSCC. In the experiments only one type of stimuli, i.e. redox chemistry, was used. ${ }^{11}$

The tristable [2] rotaxane $7^{6+}$ can be switched electrochemically between three thermodynamic states. Upon oxidation of the TTF unit, the ring $\mathbf{W}^{4+}$ must translate over the BIPY ${ }^{2+}$ unit in order to encircle the DNP unit, this pathway is activated by Coulombic repulsion. Due to this Coulombic repulsion between the ring $\mathbf{W}^{4+}$ and $\mathrm{TTF}^{\cdot+2+}$ unit, the ring $\mathbf{W}^{4+}$ passes the BIPY $^{2+}$ electrostatic barrier rapidly, and encircles the DNP. The rate of thermal relaxation of the MSCC to the GSCC, i.e. translation of the ring $\mathbf{W}^{4+}$ back from the DNP unit over the BIPY ${ }^{2+}$ electrostatic barrier to encircle the TTF unit is now decreased due to the presence of the BIPY ${ }^{2+}$ unit, therefore the conformation in which the ring $\mathbf{W}^{4+}$ is situated over the BIPY ${ }^{2+}$ unit was defined as the transition state co-conformation (TSCC); it is a thermodymically unstable state.

Rotaxane $7^{6+}$ may switch due to BIPY ${ }^{2+}$ radical-radical interactions; it was shown that upon a three-electron reduction in which two electrons are transferred to $\mathbf{W}^{4+}$, and one to the BIPY ${ }^{2+}$ unit of the thread, the resulting ring $\mathbf{W}^{2(\cdot+)}$ encircles the $\mathrm{BIPY}^{{ }^{++}}$radical cation as the most thermodynamically stable co-conformation. This translational isomer is the radical-state coconformation (RSCC). The stability of this state is due to favorable radical-radical interactions, referred to as "pimerization"; this process occurs between two or more BIPY"+ radical cations. 
For comparison purposes it should be noted that during the formation of the trisradical complex, occurring spontaneously between the ring $\mathbf{W}^{2(\cdot+)}$ and the methyl viologen radical cation $\mathbf{M V}^{\bullet+}$, the mechanism involves a bisradical intermediate $\mathbf{W}^{(\cdot+)(2+)} \cdot \mathbf{M V}{ }^{\bullet+}{ }^{40}$ This bisradical intermediate occurs as a result of spin-pairing to a singlet state, such that only two BIPY ${ }^{\bullet+}$ units $^{-}$ of the complex are paired, rendering the third unpaired BIPY ${ }^{\bullet+}$ easier to oxidize than the other two.

A similar bisradical intermediate occurs in the switching mechanism of the MIMs considered here. Due to the fact that the ring $\mathbf{W}^{(\cdot+)(2+)}$ contains BIPY ${ }^{\cdot+}$ and BIPY ${ }^{2+}$ units, the ring is both "radical-loving" and "donor loving" at the same time. This behavior leads to the shuttling of the ring $\mathbf{W}^{(\cdot+)(2+)}$ from the BIPY ${ }^{\bullet+}$ radical cation unit to the $\pi$-electron rich donor unit, i.e. TTF or DNP.

The rotaxane $7^{6+}$ incorporates both TTF and DNP recognition sites as well as the BIPY ${ }^{2+}$ unit which is situated between these two $\pi$-electron-rich sites. It is important that the BIPY ${ }^{2+}$ is situated centrally between TTF and DNP units. Upon one-electron oxidation of the trisradical RSCC state of the rotaxane $7^{6+}$, the $\mathbf{W}^{(\cdot+)(2+)}$ ring has two possibilities: it can either undergo translation a) to encircle the TTF unit or b) in the opposite direction to encircle the DNP unit. Having the knowledge that the barrier to relaxation is considerably lower in rotaxane $6^{6+}$ incorporating TTF, compared to the barrier of the rotaxane $5^{6+}$ incorporating DNP, one may expect that the translation to TTF unit will be preferred, and this behavior was confirmed by variable scan-rate experiments. $^{9}$

When zinc dust was added to the solution of the MSCC of the rotaxane $7 \cdot 6 \mathrm{PF}_{6}$ in order to reduce $\mathrm{BIPY}^{2+}$ units to their radical cations, yielding the $\mathrm{RSCC}^{40}$ the solution became purple; this behavior indicates the formation of the trisradical state. Then the zinc dust was filtered off, and when the air was bubbled through the solution in order to oxidize the BIPY ${ }^{\bullet+}$ radical cations back to BIPY ${ }^{2+}$, the purple color of the solution changed to green. The ${ }^{1} \mathrm{H}$ NMR measurement of the green solution confirmed that the rotaxane returned to the GSCC.

The rotaxanes $5^{6+}-7^{6+}$ contain a BIPY ${ }^{2+}$ unit which upon reduction serves as a radically enhanced recognition site for the $\mathbf{W}^{4+}$ ring. In rotaxanes $5^{6+}$ and $\mathbf{6}^{6+}$ the shuttling of the bisradical state co-conformation to the electron-rich unit, TTF or DNP occurs. It was shown that the shuttling of the bisradical state co-conformation to the TTF unit occurs faster than to the DNP unit. Presumably the height of the free energy barrier is dependent on the relative affinity of the adjacent $\pi$-electron-rich unit, such that the stronger the recognition, the faster the shuttling and the lower the barrier. In the tristable [2] rotaxane $7^{6+}$ the ring relaxes preferentially to the more electron-rich TTF unit, and not to the DNP unit. The above results allow to restore GSCC from the MSCC through the RSCC.

It was established that the incorporation of an electrostatic barrier between the donor recognition units in the tristable [2] rotaxane $7^{6+}$ can prolong the lifetime and stability of the MSCC; this result is promising for design of nonvolatile molecular flash memory devices. 


\section{Quaternary Azaaromatic Rotaxanes Containing Cage Macrocycles as Rings}

In this part selected examples of rotaxanes consisting of a quaternary azaaromatic thread and one or more cage macrocycles as rings are presented. First the rotaxanes with identical macrocycles are described, then follow rotaxanes containing different macrocycles as rings. The above compounds are promising e.g. for construction of molecular devices or preparation of polyrotaxanes with tailored properties.

\subsection{Rotaxanes containing identical rings}

Below, selected examples of cyclodextrin-, calixarene-, pillararene- and cucurbituril-based rotaxanes are described.

3.1.1.Cyclodextrin-based rotaxanes. 1) Recently growing attention has been paid to advanced functional materials. $^{49-52}$ In this aspect the synthesis of a supramolecular polymer, photoswitchable between a covalent and noncovalent structure has been reported. One should note that the knowledge on such systems, combining these two, covalent and noncovalent types of polymer, is today rather scarce.

In the construction of the above photoswitchable polymer, the host-guest interactions and reversible dimerization of photoactive coumarin groups was employed. First, the monomer $\mathbf{8}$, consisting of viologen, capped by two coumarin moieties was treated with $\gamma$-CD in water to give noncovalent polymer $\mathbf{N}$ by host-guest interaction between $\gamma-\mathrm{CD}$ and two coumarin units. The obtained noncovalent polymer $\mathbf{N}$ upon UV $(365 \mathrm{~nm})$ irradiation was converted into corresponding covalent polymer $\mathbf{C}$, i.e. polypseudorotaxane $\mathbf{C}$ via photoinduced cyclodimerization of coumarin. This photoinduced process is highly efficient and the formed stable cyclobutane-based coumarin dimer is generated in the cavity of $\gamma-\mathrm{CD}$. The back process, i.e. conversion of $\mathbf{C}$ into $\mathbf{N}$ was performed by UV $(254 \mathrm{~nm})$ irradiation, resulting in the photochemical cleavage of coumarin $\operatorname{dimer}^{18}$ (Scheme 9).

The synthesized polymer can serve for construction of a thermally and photochemically dual-responsive supramolecular hydrogel with the surfactant cetyl trimethylammonium bromide $(\mathrm{CTAB})$ as a cogelator. The opaque hydrogel ( $\mathrm{C}$ gel) was readily obtained by cooling the transparent aqueous solution of $\mathbf{C}$ with $\mathrm{CTAB}$ to $15^{\circ} \mathrm{C}$, while the mixture of $\mathbf{N}$ and CTAB aqueous solution cannot form a hydrogel under the same conditions.

This different gelling ability of $\mathbf{C}$ and $\mathbf{N}$ is due probably to the fact that $\mathbf{C}$ has a covalent polymer backbone acting as a physical barrier which restricts CTAB aggregations in the polymer network. However, in the $\mathbf{N}$-CTAB solution, the cavities of part of $\gamma$-CDs in $\mathbf{N}$ are occupied by alkyl chains of CTAB, therefore the $\mathbf{N}$ polymer chains may be broken.

It should be pointed out that the described synthesis of supramolecular noncovalent polymer is simple, and its advantageous feature is the use of aqueous medium. The above systems, joining the chemical advantages of two types (covalent ${ }^{53}$ and noncovalent ${ }^{54}$ ) of polymer, are promising for design of novel switchable materials with tunable properties. 

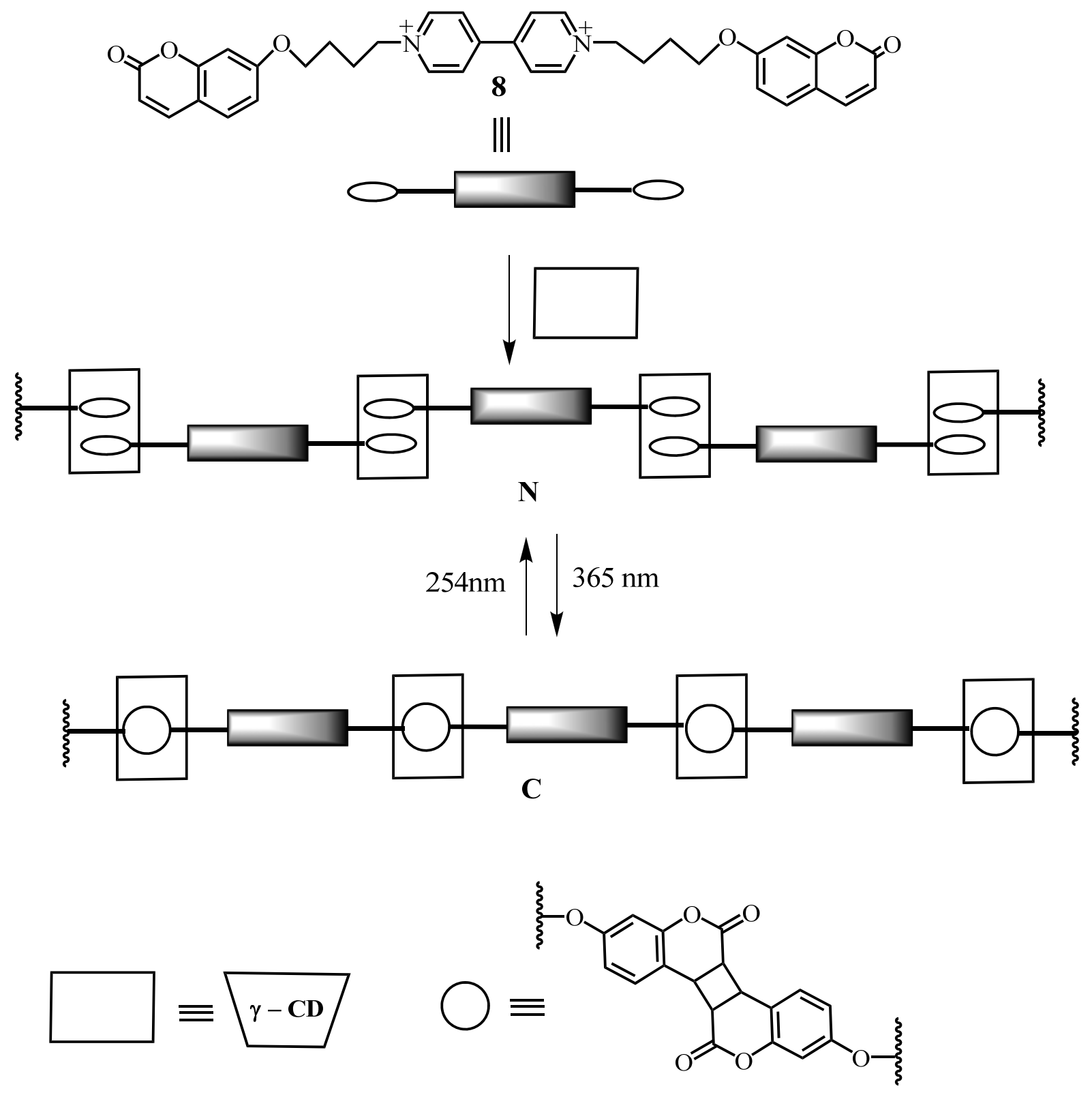

coumarin dimer

\section{Scheme 9}

2). Photoelectrochemical properties of [2] rotaxane 9 have been investigated. It is known that the presence of an extended $\pi$-conjugated system in the molecule, as well as the presence of an azo group are of importance in the design of conducting materials; rotaxanes incorporating azo group are charge-generating materials in organic photoconductors ${ }^{55}$ (Scheme 10). 


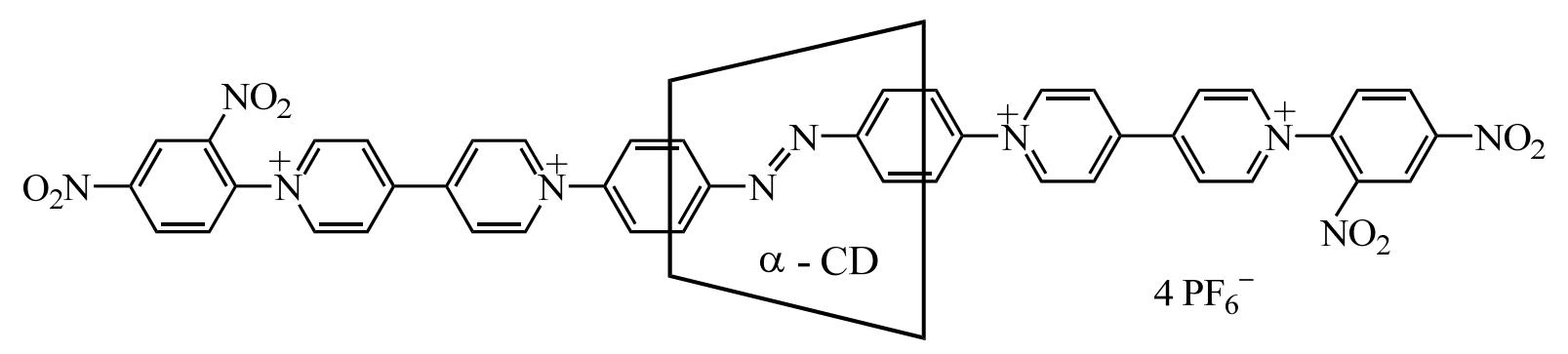

9

\section{Scheme 10}

In rotaxane $9^{56}$ the existence of the extended $\pi$-conjugated systems, the presence of azobenzene moiety as well as the presence of viologen units and 2,4-dinitrophenyl electron withdrawing aromatic stoppers result in its high photoconductivity; this is a valuable feature for use in optoelectronic and photoelectrochemical materials. Due to the possibility of the electron push-pull effect readily influenced by light stimuli, the $E / Z$ switchability and shuttling of CD ring, the rotaxane 9 is promising for optoelectronic applications. The role of light is to enhance charge transfer through the aromatic linear axis of 9; higher light intensities lead to higher photocurrents. One should also point out the high stability of 9 under irradiation conditions. In view of the above described properties, rotaxane $\mathbf{9}$ is of interest for use in new optoelectronic materials. $^{16}$

3.1.2. Calixarene-based rotaxanes. 1) It is known that the covering of metal surfaces with organic stabilizing layer is promising for design of valuable hybrid materials. In investigation concerning this research area, the anchoring of calix[6]arene-based rotaxanes and pseudorotaxanes on polycrystalline copper surfaces has been reported. This covalent functionalization of calix[6]arenes on copper was achieved by the dip-coating procedure enabling good surface coverages and copper passivation. In these studies calixarenes have been used due to their interesting properties; ${ }^{57}$ one should note that calix[6] arenes functionalized with $\mathrm{N}$-phenylureido groups have been recently used in construction of molecular machines. ${ }^{58}$

The thread components of pseudorotaxanes consisted of viologen moiety terminated by SH group, necessary for anchoring; calix[6] arene contained $N$-phenylurea units on the wide rim. The self-assembly of pseudorotaxanes from solutions, and their controlled release, were characterized by the use of XPS (X-ray photoelectron spectroscopy).

As an example the reaction of calixarene 10 with threads 11 and 12 was performed in toluene at room temperature to give pseudorotaxanes $\mathbf{1 0 \cdot 1 1}$ and $\mathbf{1 0 \bullet 1 2}$, and their toluene solutions were used for the monolayer preparation on copper. It should be pointed out that the use of suitably functionalized calixarenes in the above procedure may enable construction of interesting supramolecular systems. ${ }^{59}$ (Scheme 11) 


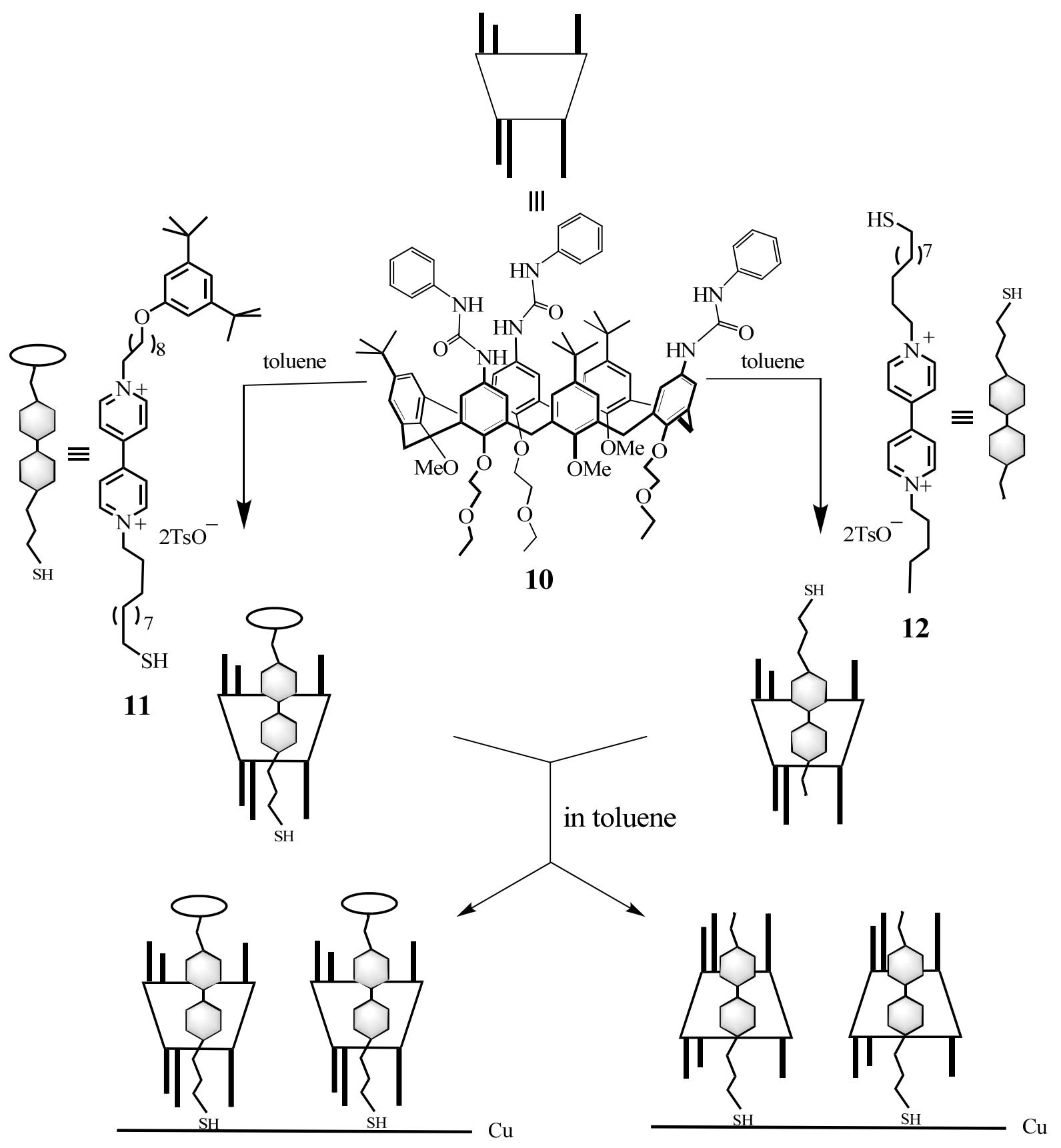

\section{Scheme 11}

2) The fluorescent supramolecular polymer $\mathbf{1 3}$ was formed from two monomers consisting of biscalixarene $\mathbf{B}$ and the decane thread terminated by a dimethylamino connector bearing a fluorophore and by viologen unit. It was found that polymer 13 can respond to both electrochemical redox and $\mathrm{pH}$ stimuli, affording pseudorotaxanes 14 and 15, respectively; it is the reversible assembly/disassembly process, which can be controlled by both redox and protonation/deprotonation processes ${ }^{60}$ (Scheme 12). 


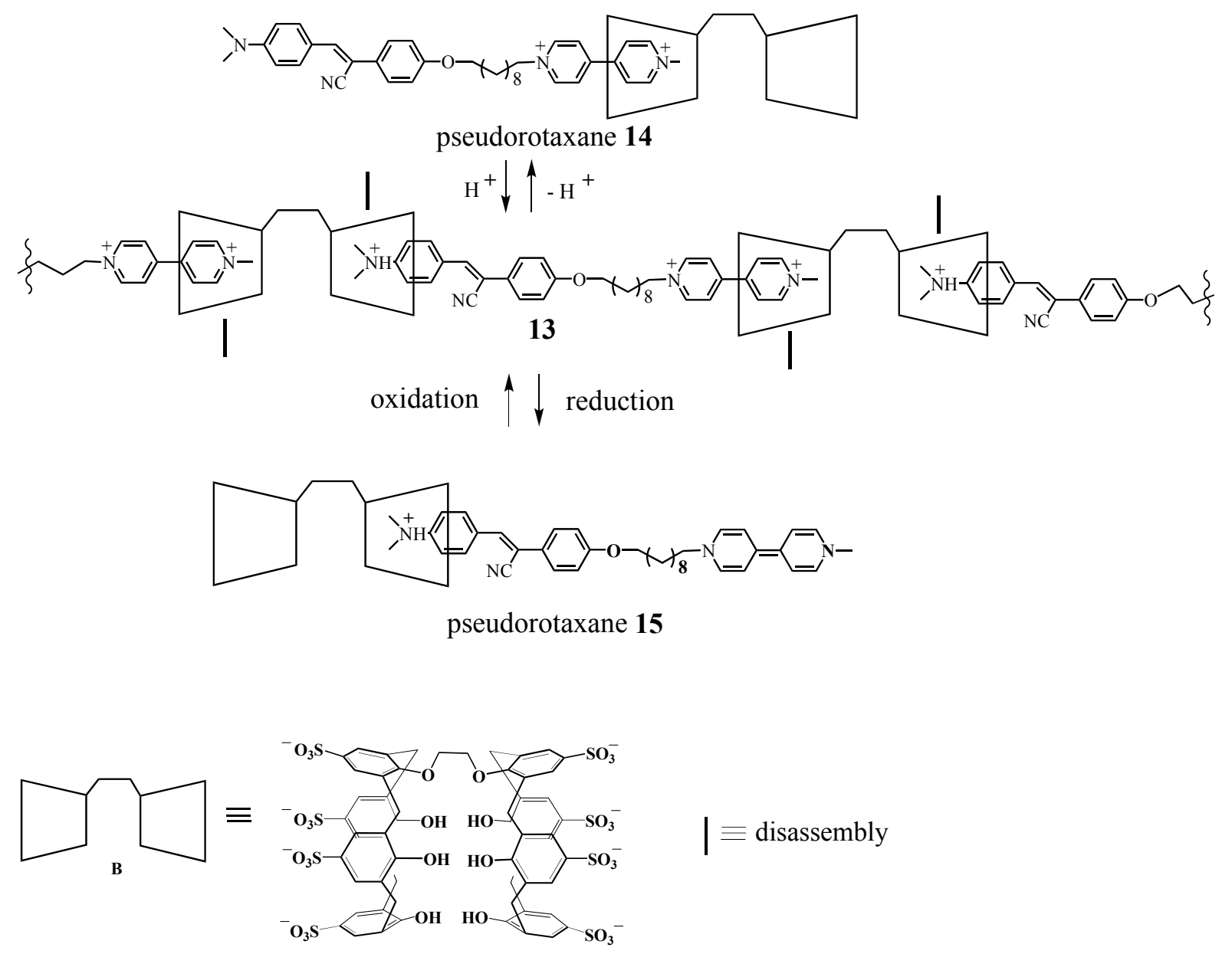

\section{Scheme 12}

Supramolecular polymers with a high molecular weight can only be prepared with high association constants. For experiments, the dimethylamine unit was chosen because after protonation it shows a high association constant with sulfonatocalix[4]arene, whereas sulfonatocalix[4]arene and viologen were chosen as host-guest pairs for their high complexation stability.

It is known that protonated dimethylamine unit associates with sulfonatocalixarene, while its deprotonation makes impossible the association process. It is known also that the stability constant of viologen with sulfonatocalix[4]arene is strongly sensitive to the redox process; it decreases sharply upon reduction of viologen from dication, via radical cation to neutral form.

Polymer 13 upon deprotonation affords pseudorotaxane 14 (protonated dimethylamine unit of $\mathbf{1 3}$ is converted into dimethylamino group which does not associate with $\mathbf{B}$ )

Polymer 13 upon reduction affords pseudorotaxane $\mathbf{1 5}$ (viologen unit of $\mathbf{1 3}$ is converted into its neutral form, which does not associate with B). Both processes, i.e. deprotonation and reduction are reversible. 
The reversibly controlled, electrochemical and $\mathrm{pH}$ stimuli responsive supramolecular polymer described above is promising for the design of polymers with special properties.

3.1.3. Pillararene-based rotaxanes. 1) Polyrotaxane 16 consisting of pillar[5]arene units and viologen polymeric chain (VP), capped on both ends by adamantyl stoppers has been synthesized by a simple one-pot procedure. First, the pillar[5] arene $\mathbf{1 7}$ and viologen polymer VP in mixed solvent DMF/acetonitrile (1:4 v/v) undergo complexation to give polypseudorotaxane. Then, upon addition of 1-adamantyl bromomethyl ketone, the pillar[5] arene-based polyrotaxane $\mathbf{1 6}$ is formed. In polyrotaxane $\mathbf{1 6}$ the pillararene hydroxyl groups are electron donors, and the viologen polymeric chain is an electron acceptor (Scheme 13).

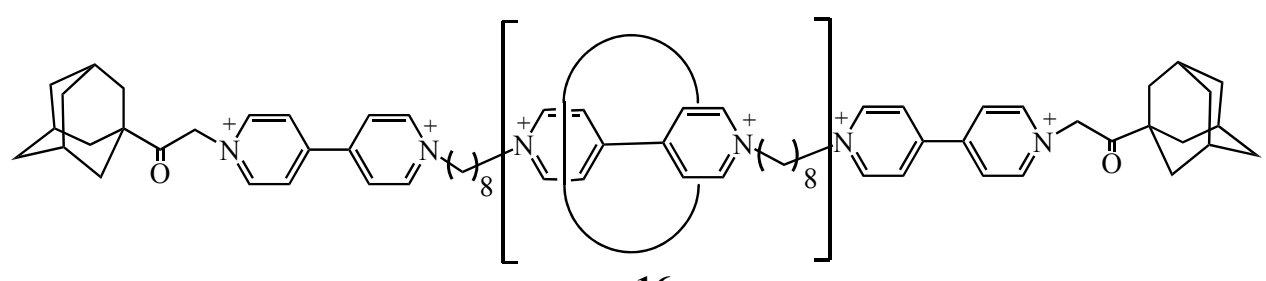

16

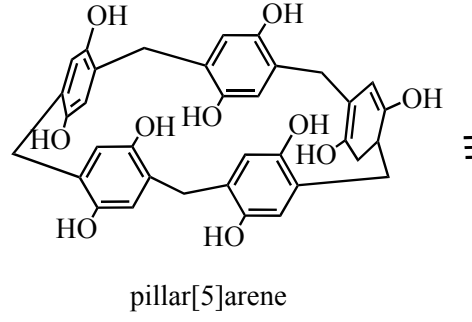

17

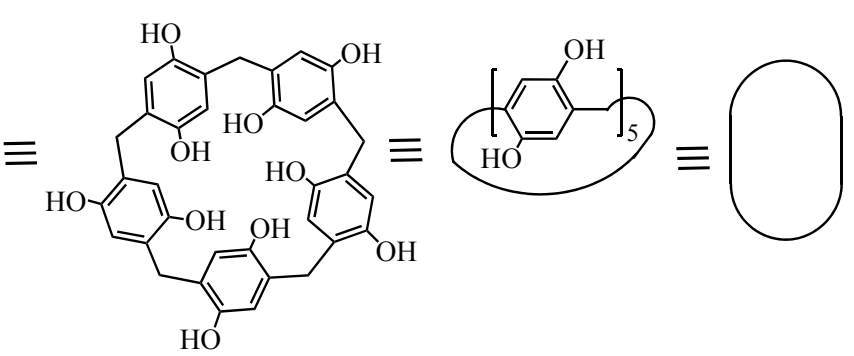

\section{Scheme 13}

One should point out the very good yield of polyrotaxane $16(93.2 \%)$, due to the high stability of the pillararene/VP complexes. Pillar[5] arene 17 consists of electron-donor hydroquinone units, therefore it shows high affinity to electron accepting molecules, such as viologens. Formation of intermolecular hydrogen bonds between hydroxyl groups of pillar[5]arenes stabilizes the structure and increases the solubility of polyrotaxane 16. Polyrotaxane 16 is soluble in DMF and DMSO, and insoluble in other organic solvents.

In the absorption spectrum of $\mathbf{1 6}$ the viologen radical cations have been detected. It is known that viologen radical cations are stabilized in the presence of excess electron donors. In 16 the electron donors of pillararenes are mechanically interlocked on the electron accepting viologen polymeric chain VP, therefore the viologen radical cations are efficiently covered by electron donors of pillararene molecules. In this way the formation of polyrotaxane $\mathbf{1 6}$ leads to stabilization of viologen radical cations. ${ }^{61}$

In 16 an intermolecular hydrogen bond between pillararenes exists, and slow shuttling occurs. Upon heating this hydrogen bond is weakened, and the shuttling of pillarenes occurs 
freely and becomes faster. It was observed that upon heating the yellow solution of polyrotaxane 16 in DMSO, the color changes into violet. The mechanism of this thermally induced color change of $\mathbf{1 6}$ was proposed as follows: when the electron donors of pillararenes cover the VP chain, the viologen radical cations are generated. However, at $20 \mathrm{C}$, due to intermolecular hydrogen bonds, the shuttling cannot be fast, therefore the viologen radical cations are only partially formed. In contrast, on heating the intermolecular hydrogen bond between pillararene molecules is weakened, and the shuttling becomes faster. Therefore, the efficient electron transfer from the electron donors of pillararenes to the electron accepting VP occurs in the whole polymer chain, and the viologen radical cations are stabilized. The cyclic voltammetry measurements have shown that on heating of polyrotaxane $\mathbf{1 6}$ the $\mathbf{V}^{2+}$ units were completely reduced to $\mathrm{V}^{\bullet+}$.

It should be noted that the described experiment is the first example of a thermally sensitive electron transfer based on polyrotaxane, while photosensitive electron transfer investigations based on supramolecular species are more common. ${ }^{62}$ The obtained polyrotaxane $\mathbf{1 6}$ is promising for the design of topological gels.

2) It was found that pillar[5]arene $\mathbf{1 7}$ forms stable[2]pseudorotaxanes with methylene $\left[-\left(\mathrm{CH}_{2}\right)_{\mathrm{n}^{-}}\right]$linked bis(pyridinium) derivatives $(\mathrm{n}=3-6), \mathbf{1 8 - 2 1}$. The determination of association constants in DMSO has shown that for the above pseudorotaxanes the $K_{a}$ values decrease in the order $19>\mathbf{2 0}>\mathbf{2 1}>\mathbf{1 8}$. The ${ }^{1} \mathrm{H}$ NMR measurements confirm these results that 19 and 20 are more suitable for 17; when the chains are longer or shorter, the association abilities decrease. It was found that 18-21 are fully encircled by pillararene 17. Meanwhile, a small part of the pyridinium ring $\left(N^{+}\right.$and $\alpha$-position) is also included in the cavity of $\mathbf{1 7 ^ { 6 3 }}$ (Scheme 14).

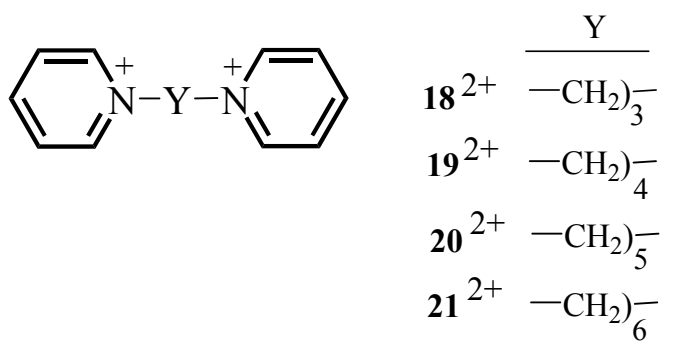

\section{Scheme 14}

3.1.4. Cucurbituril-based rotaxanes. 1) Polypseudorotaxane-type carbohydrate clusters 22-24 were synthesized by threading CB6-based carbohydrate rings on polyviologen (PV) via hostguest interactions in view of their possible use in antiadhesion therapy. It is known that the key step for the initiation of infection diseases is the adhesion of pathogenic organisms. This process is usually mediated by proteins present on the surface of the pathogenic organism, which bind to the complementary carbohydrates; these multivalent carbohydrate-protein interactions are specific and strong. 
The antiadhesion therapy in which carbohydrate clusters with strong binding ability to bacteria prevent the bacterial adhesion to host cells is a method for protecting humans from pathogenic infections. Many investigations concern the design of multivalent carbohydrate clusters able to interact with complementary proteins in dynamic biological environments, such as cell membranes. For this purpose supramolecular structures, such as pseudorotaxanes, ${ }^{64-66}$ serve as self-assembled dynamic scaffolds, which allow carbohydrate ligands to enhance their interactions with proteins.

It has been found that polypseudorotaxanes as a structure of rings on a thread offer a flexible and dynamic platform for the multivalent display of carbohydrates; the rings can freely rotate around and move along the polymer backbone. ${ }^{64}$ These features of polypseudorotaxanes give for carbohydrate ligands the possibility to find orientations optimal for interactions with their protein targets. However, today the properties of carbohydrates are evaluated by using proteins in solution, and the results may not be directly translated to their activity towards inhibition in living organisms. Therefore, for investigation of binding/inhibition properties of such multivalent carbohydrate clusters on a flexible and dynamic platform, the use of living organisms such as bacteria is necessary.

It is known that CB6 forms stable host-guest complexes with neutral or positively charged guest molecules. This property enables the synthesis of polypseudorotaxanes, in which CB6 macrocycles are threaded on various polymer chains. ${ }^{67}$ It was found that the water-soluble polypseudorotaxanes consisting of CB6 macrocycles threaded on PV are stable against dethreading without use of bulky stoppers.

In the experiments, three CB6-based mannose-polypseudorotaxanes 22-24 having 10, 5 and 3 CB6Man rings on the PV thread were obtained by treatment of the corresponding amounts of CB6Man with PV having approximately 11 viologen units. It was found that $\mathbf{2 2 - 2 4}$ effectively induce bacterial aggregation and show high inhibitory activity against bacterial binding to host cells. The specific and multivalent interactions with E.coli ORN 178 of 22-24 have been demonstrated. It was established that $\mathbf{2 2 - 2 4}$ are much more effective than the CB6-based mannose ring (CB6Man) in bacterial aggregation and hemagglutination inhibition; 24 showed to be more effective than $\mathbf{2 2}$ and $\mathbf{2 3}$. The obtained results suggest that 22-24 are promising for application in antiadhesion therapy ${ }^{68}$ (Scheme 15).

2) Investigations are aiming today to develop methods for altering the properties of cucurbituril receptors. It is known that CB8 may bind two guests simultaneously to give heteroternary complexes CB8-X-Y. In these complexes the binding occurs sequentially, and the properties of the first guest $X$ (solubility, optical activity) influence the properties of the resulting $\mathrm{CB} 8 \cdot \mathrm{X}$ complex, which then acts as a receptor for the second guest $\mathrm{Y}$. However, the ability of the $\mathrm{CB} 8 \cdot \mathrm{X}$ complex to dissociate before binding $\mathrm{Y}$ is a limitation. To overcome this difficulty, $\mathrm{CB} 8$ was mechanically linked to $\mathrm{X}$ as a rotaxane.

There exist many $\mathrm{CBn}$-based rotaxanes; ${ }^{69}$ here the example of CB8-based rotaxane is described. An important advantage of CB8 rotaxane as compared to lower CBn rotaxanes $(n<8)$, is that $\mathrm{CB} 8$ rotaxane can bind a second guest while not allowing dissociation of the first guest. In 
the investigations there was observed that viologen promotes the selective binding of a second guest. Since CB8 is large, the large stoppers are necessary, as those tetraphenylmethane units were employed.

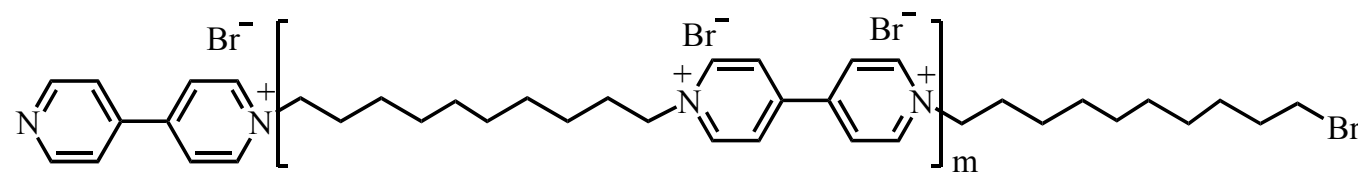

polyviologen $(\mathrm{PV}), \mathrm{m} \sim 10$

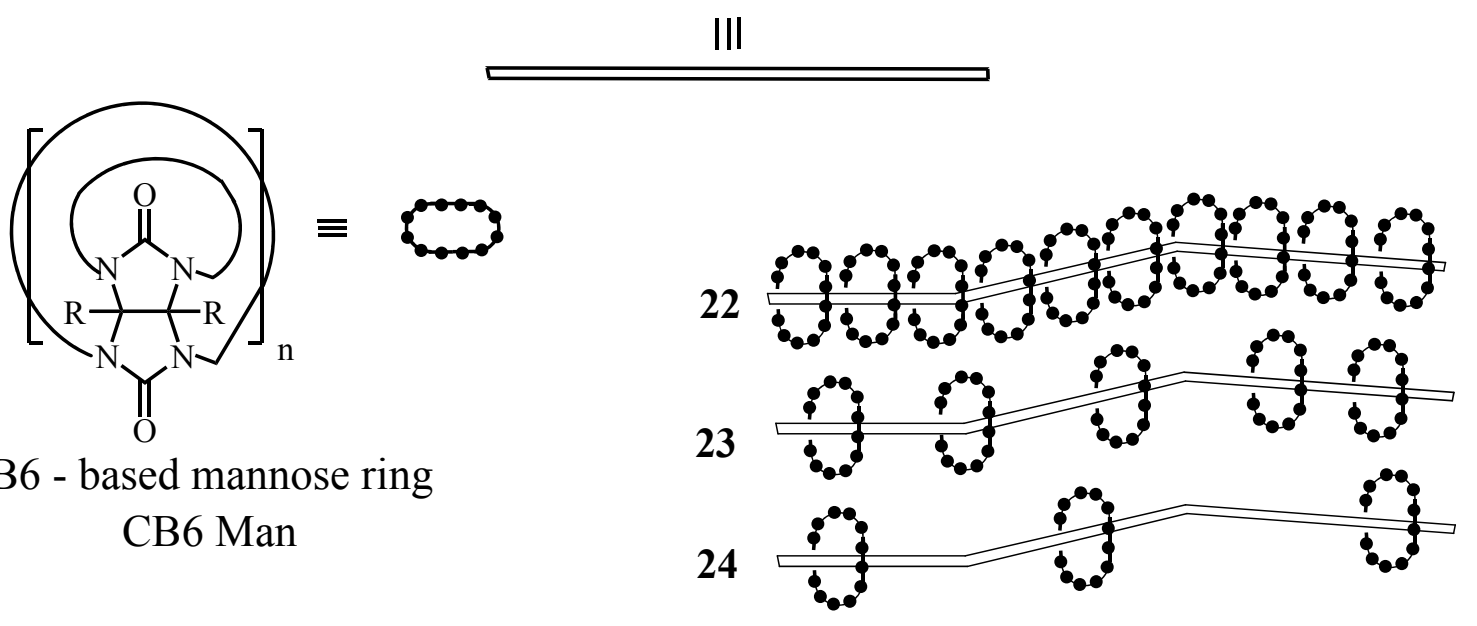

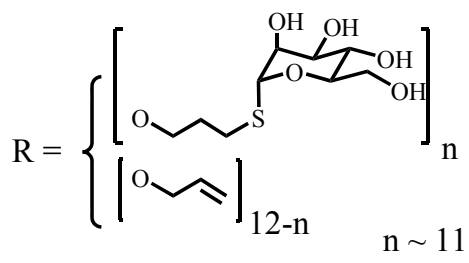

\section{Scheme 15}

The experiment begins with the reaction of 4,4'-dipyridyl with azide 25 affording the viologen 26, which upon treatment with $\mathrm{CB} 8$ in water followed by $\mathrm{KPF}_{6}$ yields pseudorotaxane 27. The subsequent click reaction of $\mathbf{2 7}$ with stopper group $\mathbf{2 8}$ produces rotaxane $\mathbf{2 9}$. Rotaxane 29 is insoluble in water due to the hydrophobicity of the stopper groups; however, it is soluble in acetonitrile and DMSO. Rotaxane 29 was titrated with a second guest, i.e. 2,6-dihydroxynaphthalene 30 in acetonitrile-D3 solutions for ${ }^{1} \mathrm{H}$ NMR measurements; they showed the formation of the $\mathbf{2 9 \cdot 3 0}$ complex, in which cucurbituril binds simultaneously viologen and $\mathbf{3 0}$. The presence of $\mathbf{2 9 \cdot 3 0}$ was confirmed by ESI mass spectrometry.

In order to obtain a water-soluble rotaxane, the stopper groups of rotaxane $\mathbf{2 9}$ were modified by electrophilic substitution. To this end the organic-soluble rotaxane 29 was treated with chlorosulfonic acid to afford sulfonated rotaxane 31. It was found that $\mathbf{3 1}$ was soluble in water up to a concentration of $\sim 15 \mathrm{mM}, 1000$-fold higher than CB8 and 10-fold higher than the 
analoguous CB8 $\mathbf{3 2}$ complex. This result shows that a single modification of the threaded guest of 29 was sufficient to alter the solubility of $\mathbf{2 9}$ from aqueous insoluble to highly water-soluble. ${ }^{70}$

The substantial changes in the ${ }^{1} \mathrm{H}$ NMR spectrum of $\mathbf{3 1}$ in the presence of small amounts of second guest have indicated that binding was much stronger in aqueous solution than observed for 29 in acetonitrile-D3. Since in CB8 $\mathbf{3 2}$ upon binding of second guests $\mathbf{3 0}, \mathbf{3 3}$ or 34, the quenching of naphthalene or indole fluorescence occurs, it is possible to monitor the binding of these guests to $\mathbf{3 1}$ by use of fluorescence spectroscopy. In such experiments it was found that rotaxane 31 binds the second guest with fluorescence quenching, in a similar fashion as in the case of $\mathrm{CB} 8 \mathbf{\bullet 2}$, and that the viologen portion of the rotaxane and the second guest are in close proximity in the cucurbituril cavity. It was established that the binding affinity of $\mathbf{3 1}$ to a second guest in aqueous buffer is $>1000$-fold stronger than that of $\mathbf{2 9}$ in acetonitrile-D3 (Scheme 16).

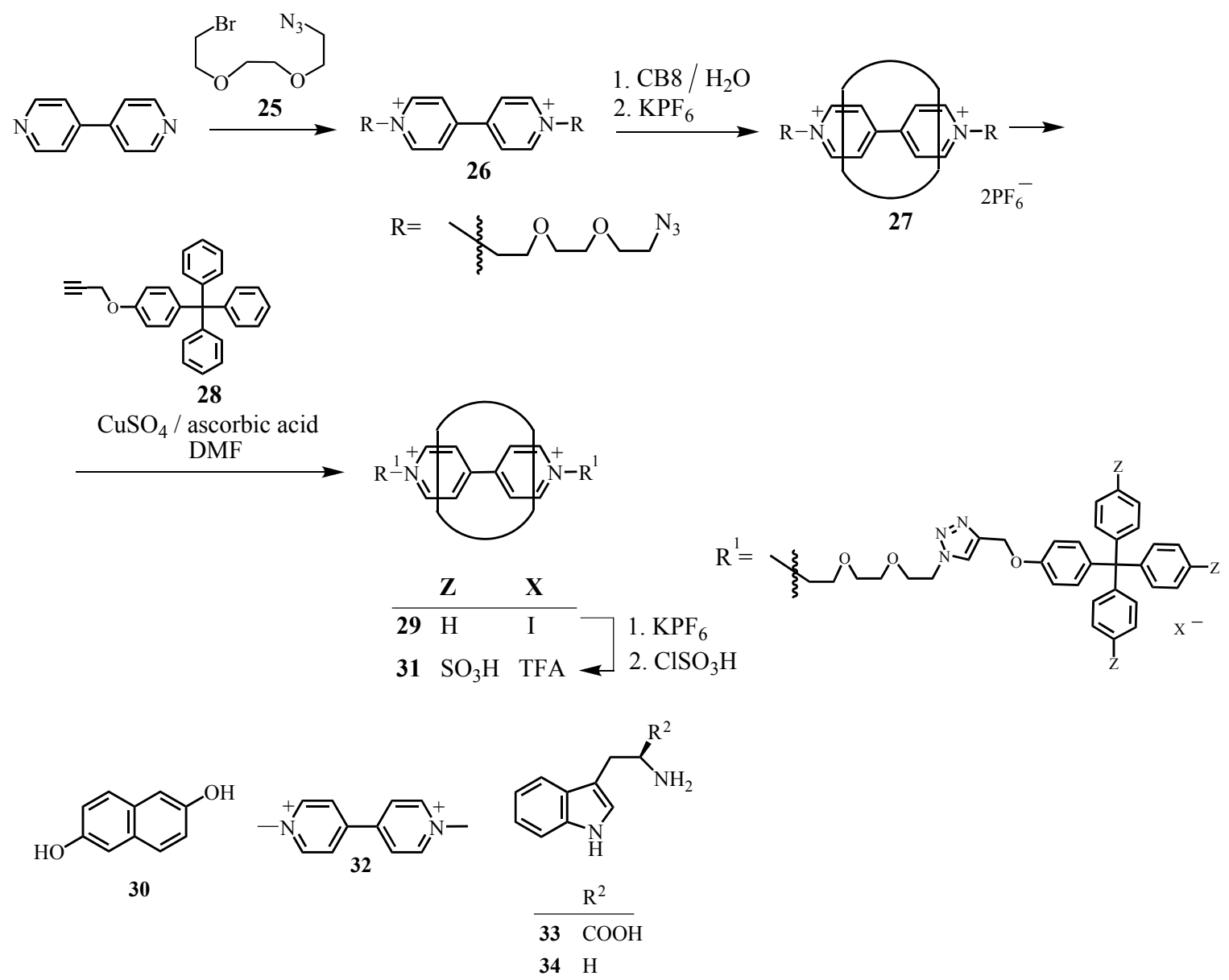

\section{Scheme 16}

The CB8 rotaxanes reported above are a new class of artificial receptors binding neutral and cationic guests with high affinity in aqueous solution. It should be noted that the water-soluble rotaxane 31 behaves similarly to the CB8 $\mathbf{3 2}$ complex but does not dissociate and therefore can be used under large variety of conditions. The threaded guest may undergo modifications to 
change the properties of the receptor, as shown by substantially altering the solubility and binding properties of rotaxane 29. The described modification of the threaded guest is promising for conjugation of cucurbiturils to solid support ${ }^{71}$ and enables changes in properties of receptors, overcoming their difficult modification. The above study presents a new approach to artificial receptors with readily modifiable properties.

3) It is known that shuttling in bistable rotaxanes requires an external stimulus. An alternate and autonomous mechanism involves the coupling of the shuttling process to an oscillating chemical reaction. Oscillating reactions are a class of a dynamic self-assembly. However, in the reported work the oscillating reactions were not used, instead the experiments were performed in aqueous systems, and thus $\mathrm{pH}$ oscillations were employed. In this system $\mathrm{pH}$ of the solution is altered in a cyclic manner, switching the rotaxane between the two states. As a result, as long the oscillation is sustained, the molecular machine can switch autonomously between these two states. Only a few systems exist where $\mathrm{pH}$ oscillates in a controlled manner, one of them is the used here thiosulfate/sulfite/iodide system, which displays the high amplitude.

To demonstrate the operation of such an autonomous system, the target pseudorotaxane 35 was synthesized. In 35 the cucurbituril CB7 serves as a ring. It should be noted that cucurbiturils have good host properties, ${ }^{72}$ they form highly stable complexes with aromatic amines and quatemary pyridinium compounds ${ }^{73}$ and serve for construction of molecular switches and machines. $^{74,75}$

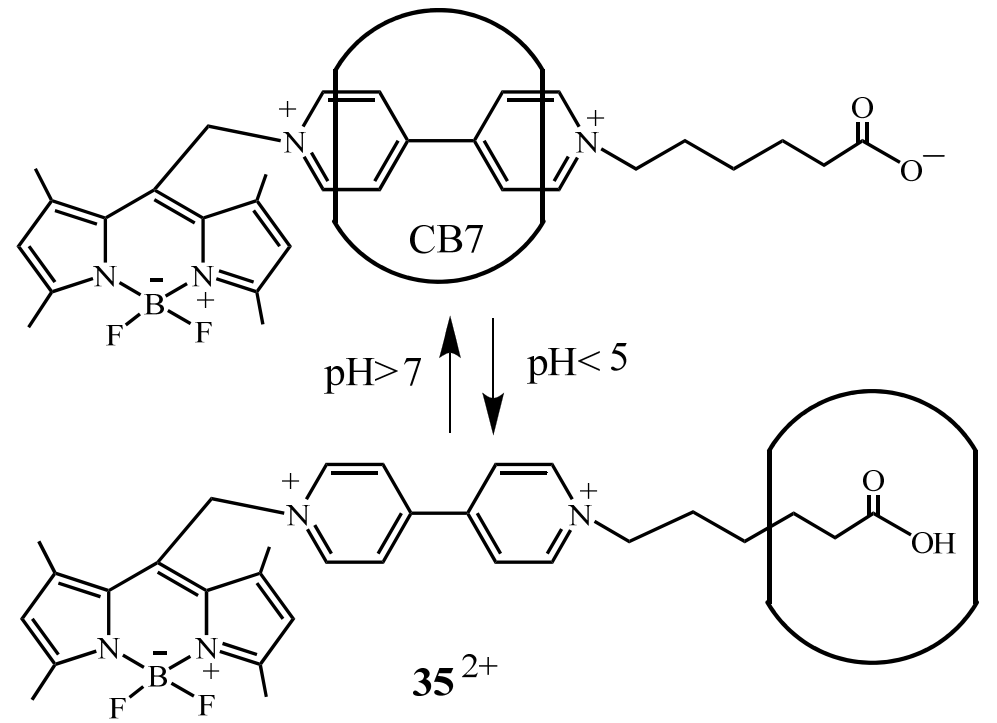

\section{Scheme 17}

The thread of $\mathbf{3 5}$ bears a viologen unit, a carboxylic group and a Bodipy derivative, which is a convenient fluorophore. ${ }^{76}$ The Bodipy unit is a fluorescent reporter of the position of cucurbituril on the thread, and it serves as a stopper at one end of $\mathbf{3 5}$. The viologen and carboxylic acid units are two binding sites for CB7. Under basic conditions, cucurbituril prefers 
the viologen station, and under acidic conditions the protonated carboxylate group is the preferred station for cucurbituril. In the above shuttle system, the CB7 is shuttling from one station to the other in an autonomous fashion. It is a demonstration of autonomous shuttling occurring in the pseudorotaxane in an oscillating $\mathrm{pH}$ system ${ }^{13}$ (Scheme 17).

\subsection{Rotaxanes containing different rings}

In this section selected examples of cyclodextrin/calixarene-, cyclodextrin/cucurbituril- and cyclodextrin/calixarene/cucurbituril-based rotaxanes will be described.

3.2.1. Cyclodextrin/calixarene-based rotaxane. The construction of a light-driven linear chiral supramolecular polyrotaxane $\mathbf{3 8}$ was reported. In the synthesis, first the monomer $\mathbf{3 6}$ formed with $\alpha-C D$ in water the polypseudorotaxane 37 which contains an axially chiral 1,1'-binaphthyl unit and two in $\alpha-C D$ included azobenzene arms, terminated by viologen groups. The components of $\mathbf{3 7}$ have very high host-guest stability, and they form a main-chain supramolecular polymer in water. ${ }^{60,77}$ The encapsulation of azobenzene moieties of monomers 36 by hydrophilic $\alpha$-CD macrocycles increases their water solubility. The subsequent host-guest recognition of pseudorotaxane $\mathbf{3 7}$ with biscalixarene $\mathbf{B}$ in water afforded polyrotaxane $\mathbf{3 8}$. (Scheme 18)

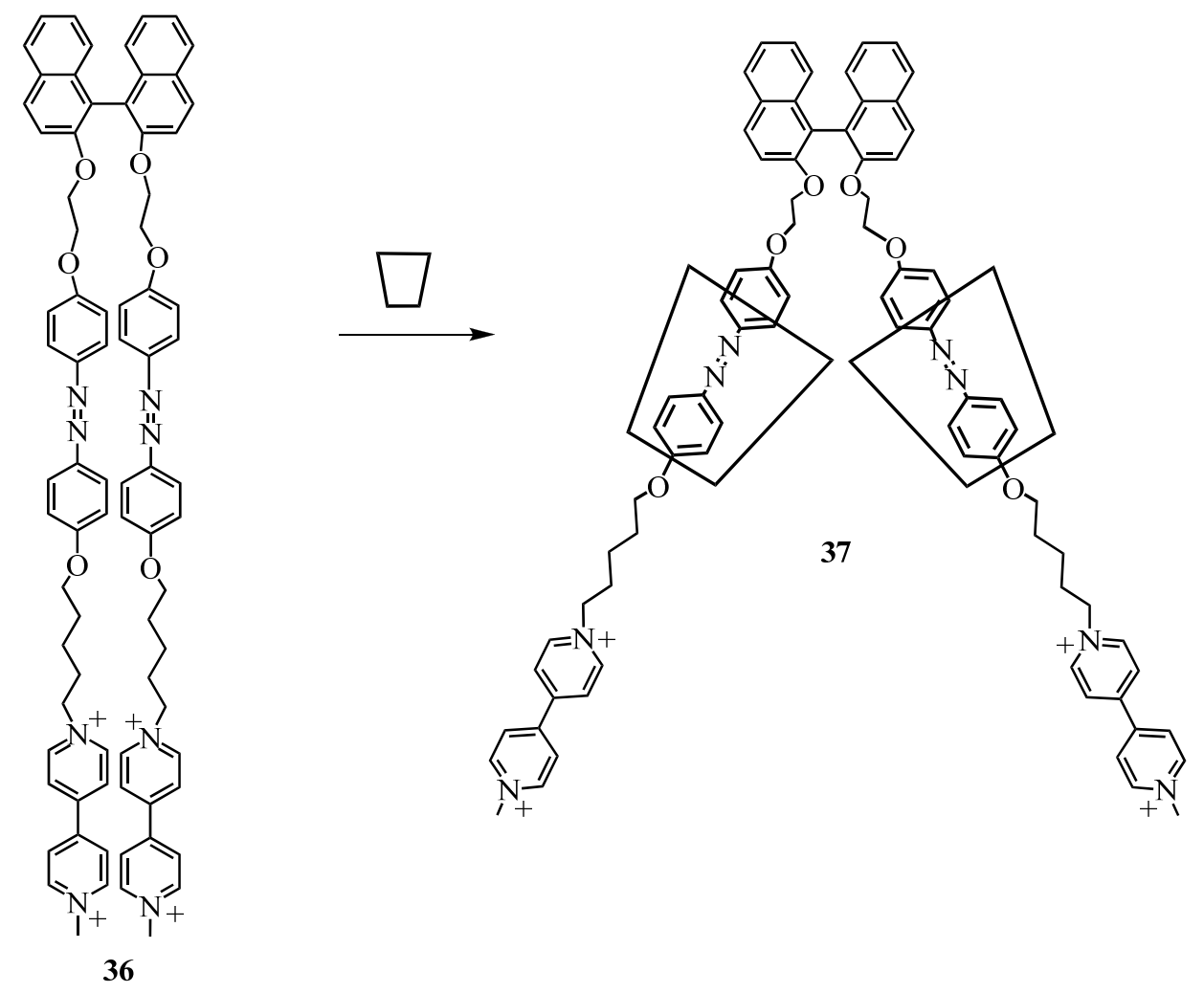

\section{Scheme 18a}




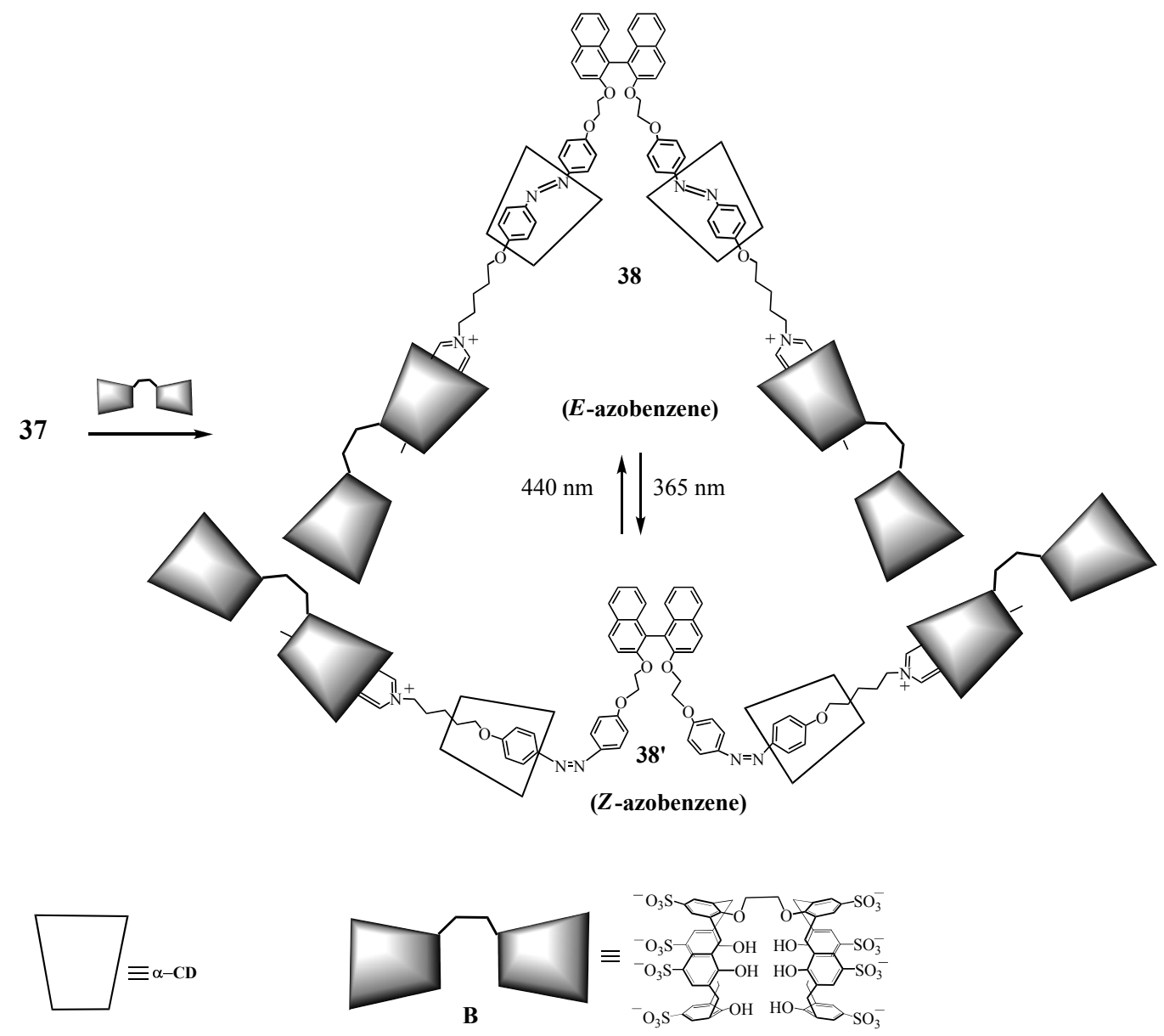

\section{Scheme 18b}

The UV (365nm) irradiation of 38 containing (E)-azobenzene units induces the $E / Z$ photoisomerization of azobenzene which makes the $\alpha-C D$ move away from the azobenzene, due to its change from the $E$ configuration into $Z$, affording polyrotaxane $\mathbf{3 8}^{\prime}{ }^{78}$ The process is reversible, the UV (440nm) irradiation of $\mathbf{3 8}^{\prime}$ leads back to 38. To confirm the photoresponsive structure of 38, the preliminary modeling was performed using calculations at the B3LYP level. $^{79}$

The structure of the light-driven chiral polymer $\mathbf{3 8}$ molecules in water was directly observed in their native state using cryo-TEM (transmission electron spectroscopy) measurements. They are the first dynamically self-assembled, light driven single helical linear molecules with lengths of hundreds of nanometers to micrometers. The above described results are promising for the design of supramolecular polyrotaxanes with tailored properties.

3.2.2. Cyclodextrin/cucurbituril-based rotaxane. It was observed that the integration of two inclusion complexes: $\beta-\mathrm{CD}$ with 2,6-dihydroxynaphthalene 30, i.e. $\beta-\mathrm{CD} \cdot 30$ and $\mathrm{CB} 8$ with viologen bearing adamantane moiety 39, i.e. CB8•39 affords [3]pseudorotaxane 40 containing 
$\mathrm{CD}$ and $\mathrm{CB}$ rings. In $\mathbf{4 0}$ the driving forces are the simultaneous $\mathrm{CT}$ interaction of $\mathbf{3 0}$ with the viologen moiety of $\mathbf{3 9}$ in the cavity of CB8 and the molecular recognition of adamantane moiety of 39 by $\beta-C D .^{80}$

Upon mixing complexes $\beta-\mathrm{CD} \cdot 30$ with $\mathrm{CB} 8 \cdot 39$ in $\mathrm{D}_{2} \mathrm{O}$ solution, the $\mathrm{CB} 8$ moves to the viologen moiety of $\mathbf{3 9}$, facilitating the formation of stable $\mathrm{CT}$ complex between $\mathbf{3 0}$ and viologen moiety of 39 in the CB8 cavity, and simultaneously the adamantane moiety of $\mathbf{3 9}$ enters into the $\beta$-CD cavity. This observation confirms previous studies describing the fact that CB8 can facilitate the formation of stable CT complexes between hydroxynaphthalenes and viologens ${ }^{81}$. (Scheme 19)

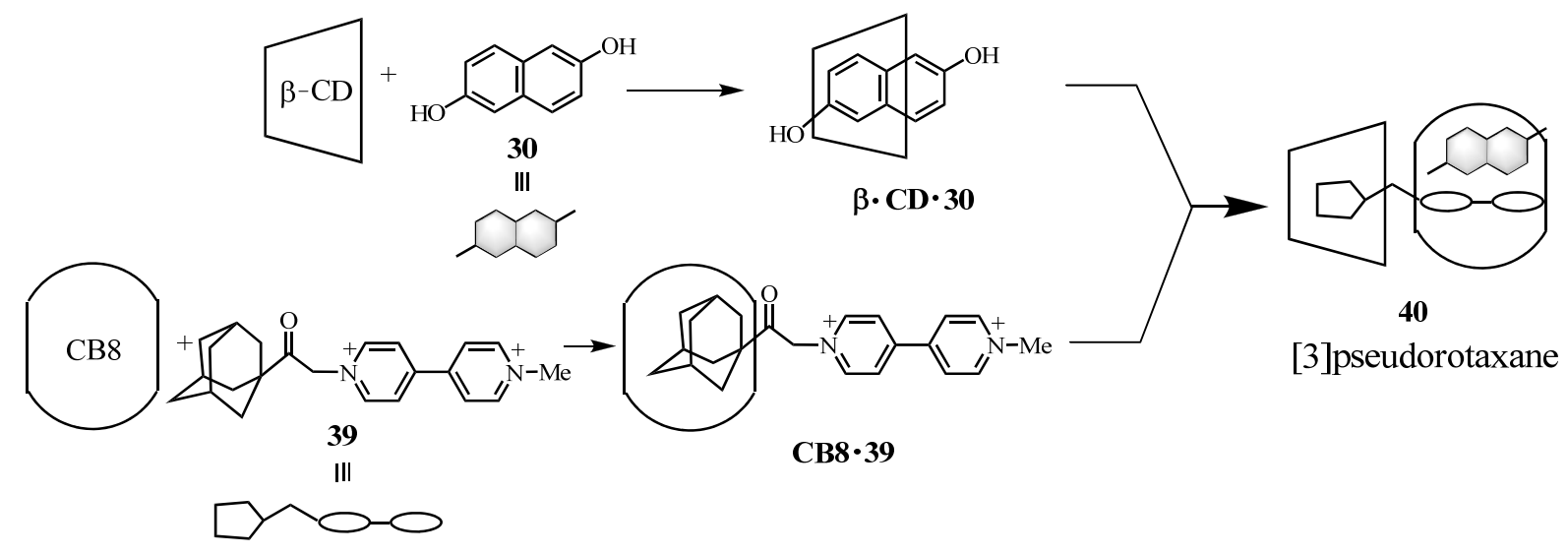

\section{Scheme 19}

3.2.3. Cyclodextrin/calixarene/cucurbituril-based rotaxane. Pseudo[4]rotaxanes containing three rings, two or three different, have been synthesized and characterized. In the experiments the thread 41 incorporating a central azobenzene unit and two terminal viologen units was used, and as rings served $\alpha$-cyclodextrin ( $\alpha$-CD), $p$-sulfonatocalixarene (cal) and cucurbit[7]uril (CB7). The syntheses have been performed in aqueous solution. The treatment of 41 with $\alpha$-CD affords pseudo[2]rotaxane 42 in which $\alpha-C D$ encircles the azobenzene moiety. It is known that cal and CB7 prefer the binding with viologen over azobenzene, therefore the treatment of $\mathbf{4 1}$ with cal and CB7 yielded pseudo[3] rotaxanes 43 and 44, respectively. The binding of viologen by cal and CB7 proceeds with very high association constants.

The reaction of 42 with cal and CB7 affords pseudo[4]rotaxanes 45 and 46 respectively, and reaction of $\mathbf{4 2}$ with $\mathrm{CB} 7$, followed by cal leads to pseudo[4]rotaxane $\mathbf{4 7}$. Having in view the high association constants of cal and CB7 with terminal viologen groups, the above three pseudo[4]rotaxanes 45-47 may be regarded as $\alpha$-CD based [2]rotaxanes with cal and CB7 units, respectively, acting as stoppers. ${ }^{82}$ (Scheme 20 ) 

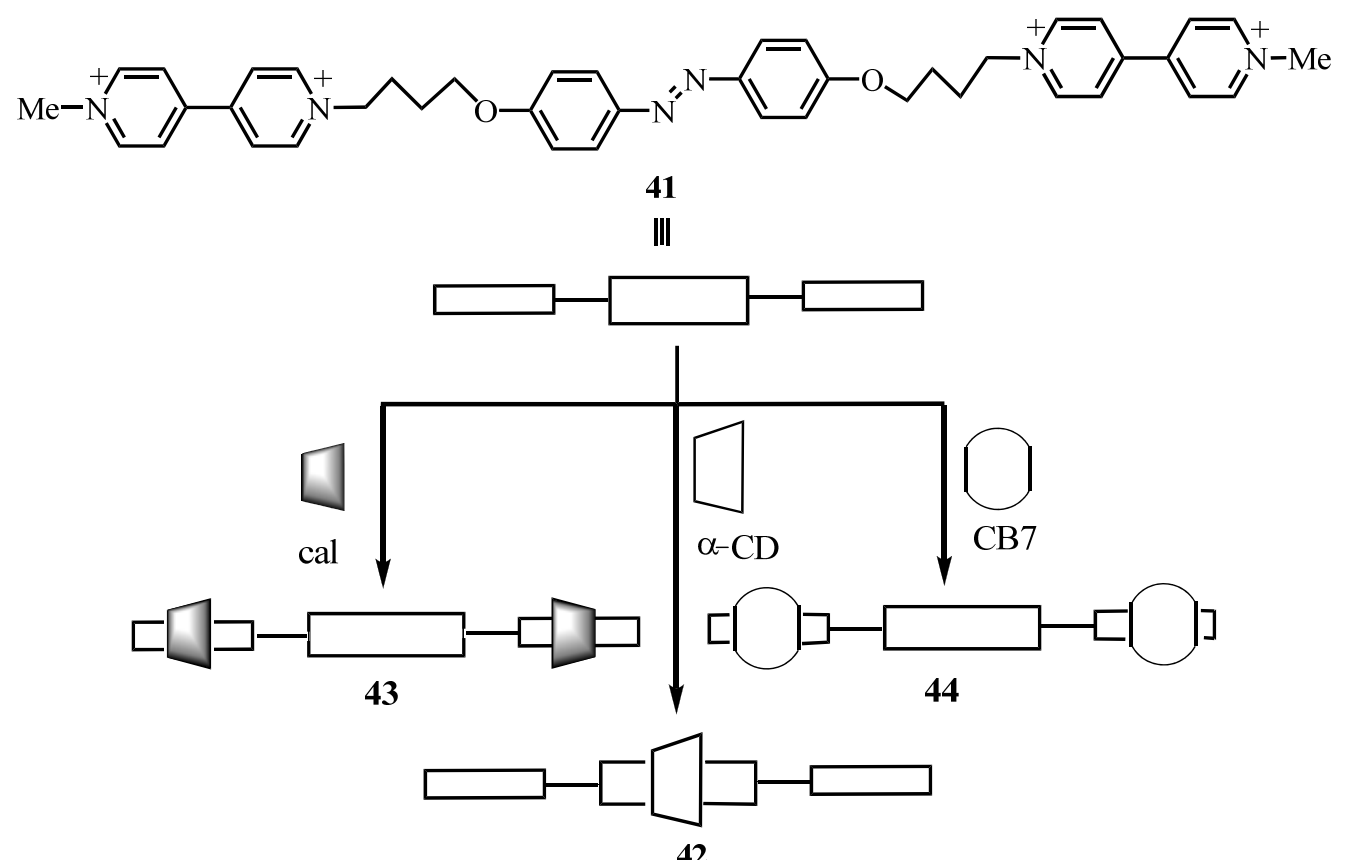

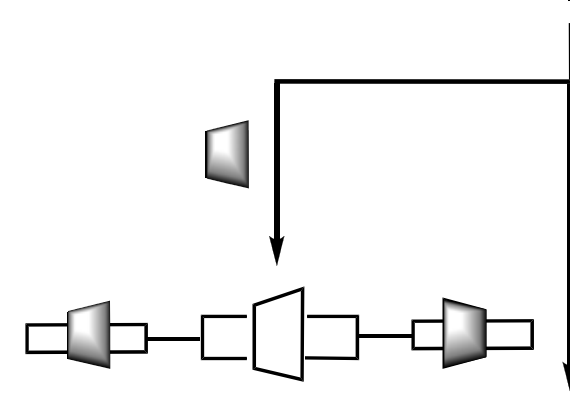

45

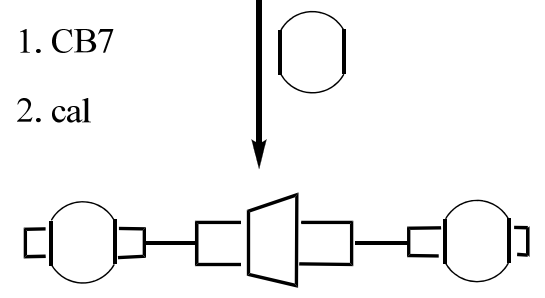

46<smiles>C#Cc1cc(S(N)(=O)=O)cc(C=C)c1O</smiles>

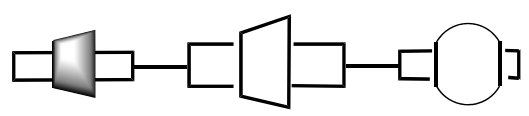

47

\section{Scheme 20}

It is known that the induced circular dichroism (ICD) signal appears when a chiral host includes an achiral guest. The signals of 45-47 result from the induction of chiral $\alpha-C D$ on achiral azobenzene moiety; the azobenzene units are encircled by $\alpha-\mathrm{CD}$ molecules, and their transition dipole moments are parallel to the axes of the chiral $\alpha-C D$ cavities. Since cal and CB7 have symmetrical cavities without chirality, the pseudorotaxanes $\mathbf{4 3}$ and $\mathbf{4 4}$ do not generate ICD signals.

The irradiation of aqueous solutions of 45-47 at $360 \mathrm{~nm}$ results in $E / Z$ photoisomerization of azobenzene units from $E$ to $Z$ form, and as a consequence the shuttling of $\alpha$-CD molecules 
occurs. The $E / Z$ photoisomerization of azobenzene is reversible, the $430 \mathrm{~nm}$ irradiation leads back to $E$ forms of 45-47. The investigation of the above pseudo[3]- and [4]rotaxanes is promising for design of molecular devices.

\section{Conclusions}

The rotaxanes and polyrotaxanes are today a topic of intense study, finding its reflection in an enormous amount of reports. ${ }^{83-85}$

One should be aware of the importance of radical-radical rotaxanes in various fields, e.g. the design of nanoelectromechanical systems (NEMs) ${ }^{8}$ and nonvolatile molecular memory devices; ${ }^{9}$ consequent development of research concerning these rotaxanes is to be expected.

Growing attention is paid today to cyclodextrin-based rotaxanes, ${ }^{86,87}$ and especially to cyclodextrin-based polyrotaxanes, ${ }^{88-95}$ interesting for their valuable properties.

Another class is the calixarene-based rotaxanes. ${ }^{96-99}$ One should note the large variety of calixarenes ${ }^{100,101}$ and related compounds, such as resorcinarenes, ${ }^{102,103}$ cavitands, ${ }^{104,105}$ capsules, ${ }^{106-108}$ pillararenes ${ }^{109-111}$ and noria. ${ }^{112,113}$ Noria are obtained by simple one-pot condensation of resorcinol with alkanedials, similar to that leading to calixarenes; an example are those synthesized by using 1,5-pentanedial. Noria are unique double-cyclic oligomers with ladderlike links between the two rings, forming a large hydrophobic central cavity; they resemble the structure of a waterwheel (noria is the Latin for waterwheel). Noria and their derivatives show selective adsorption of $\mathrm{CO}_{2}$ over $\mathrm{H}_{2}$ and $\mathrm{N}_{2}$ and are promising in application as UVcurable materials. ${ }^{112}$

There exist many rotaxanes containing cage macrocycles other than cyclodextrins or calixarenes. Among them one may mention pillararene- ${ }^{114,115}$ and cucurbituril- ${ }^{116-118}$ based rotaxanes, as well as cyclodextrin/cucurbituril-based rotaxanes. ${ }^{119,120}$

In consideration of the great extent of work on rotaxanes, it is not possible to cover all reports dealing with this topic; this review is not exhaustive, but one may hope that to some extent it may be helpful in a dissemination of knowledge of this interesting research area.

\section{Acknowledgements}

This work is a part of the project no. 2011/01/D/ST5/05781. The authors gratefully acknowledge Polish National Science Centre for financial support of this project.

\section{References}

1. Deska, M.; Nowik-Zajac, A.; Sliwa, W. Arkivoc 2013, (i), 185. 


\section{http://dx.doi.org/10.3998/ark.5550190.0014.107}

2. Li, H.; Fahrenbach, A. C.; Coskun, A.; Zhu, Z.; Barin, G.; Zhao, Y-L.; Botros, Y. Y.; Sauvage, J-P.; Stoddart, J. F. Angew. Chem. Int. Ed. 2011, 50, 6782.

http://dx.doi.org/10.1002/anie.201102510

PMid:21717550

3. Qu, D-H.; Tian, H. Chem. Sci. 2011, 2, 1011.

http://dx.doi.org/10.1039/c0sc00653j

4. Martinez, A.; Ortiz, M. C.; Garcia, F.; Jose, M. Chem. Soc. Rev. 2013, 42, 4746.

http://dx.doi.org/10.1039/c2cs35424a

PMid:23340678

5. Gaeta, C.; Talotta, C.; Margarucci, L.; Casapullo, A.; Neri, P. J. Org. Chem. 2013, 78, 7627.

http://dx.doi.org/10.1021/jo401206j

PMid:23834296

6. Ogoshi, T.; Yamagishi, T. Bull. Chem. Soc. Japan 2013, 86, 312.

http://dx.doi.org/10.1246/bcsj.20120245

7. Pessego, M.; Moreira, J. A.; Da Costa, A. M. R.; Corrochano, P.; Poblete, F. J.; Garcia-Rio, L. J. Org. Chem. 2013, 78, 3886.

http://dx.doi.org/10.1021/jo400295k

PMid:23510333

8. Li, H.; Zhu, Z.; Fahrenbach, A. C.; Savoie, B. M.; Ke, C.; Barnes, J. C.; Lei, J.; Zhao, Y-L.; Lilley, L. M.; Marks, T. J.; Ratner, M. A.; Stoddart, J. F. J. Am. Chem. Soc. 2013, 135, 456. http://dx.doi.org/10.1021/ja310060n

PMid:23163704

9. Fahrenbach, A. C.; Zhu, Z.; Cao, D.; Liu, W-G.; Li, H.; Dey, S. K.; Basu, S.; Trabolsi, A.; Botros, Y. Y.; Goddard III, W. A.; Stoddart, J. F. J. Am. Chem. Soc. 2012, 134, 16275.

http://dx.doi.org/10.1021/ja306044r

PMid:23002805

10. Zhang, W.; DeIonno, E.; Dichtel, W. R.; Fang, L.; Trabolsi, A.; Olsen, J-C.; Benítez, D.; Heath, J. R.; Stoddart, J. F. J. Mater. Chem. 2011, 21, 1487.

http://dx.doi.org/10.1039/c0jm02269a

11. Coskun, A.; Banaszak, M.; Astumian, R. D.; Stoddart, J. F.; Grzybowski, B. A. Chem. Soc. Rev. 2012, 41, 19.

http://dx.doi.org/10.1039/c1cs15262a

PMid:22116531

12. Hess, H.; Dumont, E. L. P. Small 2011, 7, 1619.

http://dx.doi.org/10.1002/sm11.201100240

PMid:21574250

13. Buyukcakir, O.; Yasar, F. T.; Bozdemir, O. A.; Icli, B.; Akkaya, E. U. Org. Lett. 2013, 15, 1012. 


\section{$\underline{\text { http://dx.doi.org/10.1021/o1303495n }}$}

PMid:23398309

14. Wilson, D. A.; Nolte, R. J. M.; van Hest, J. C. M. Nat. Chem. 2012, 4, 268.

http://dx.doi.org/10.1038/nchem.1281

PMid:22437710

15. Guo, D-S.; Zhang, T-X.; Wang, Y-X.; Liu, Y. Chem. Commun. 2013, 49, 6779.

http://dx.doi.org/10.1039/c3cc41918e

PMid:23785710

16. Deligkiozi, I.; Papadakis, R.; Tsolomitis, A. Phys. Chem. Chem. Phys. 2013, 15, 3497.

http://dx.doi.org/10.1039/c3cp43794a

PMid:23361123

17. Rydzek, G.; Garnier, T.; Schaaf, P.; Voegel, J-C.; Senger, B.; Frisch, B.; Haikel, Y.; Petit, C.; Schlatter, G.; Jierry, L.; Boulmedais, F. Langmuir 2013, 29, 10776.

http://dx.doi.org/10.1021/la402454e

PMid:23895332

18. Zhang, Q.; Qu, D-H.; Wu, J.; Ma, X.; Wang, Q.; Tian, H. Langmuir 2013, 29, 5345.

http://dx.doi.org/10.1021/la4012444

PMid:23560858

19. Jacquot de Rouville, H-P.; Ieh1, J.; Bruns, C. J.; McGrier, P. L.; Frasconi, M.; Sarjeant, A. A.; Stoddart, J. F. Org. Lett. 2012, 14, 5188.

http://dx.doi.org/10.1021/o13022963

PMid:23057862

20. Zheng, B.; Wang, F.; Dong, S.; Huang, F. Chem. Soc. Rev. 2012, 41, 1621.

http://dx.doi.org/10.1039/c1cs15220c

PMid:22012256

21. Wu, S.; Wang, G.; Zou, L.; Wang, Q.; Ma, X. Dyes Pigm. 2012, 95, 436.

http://dx.doi.org/10.1016/j.dyepig.2012.04.020

22. Thomsson, D.; Sforazzini, G.; Anderson, H. L.; Scheblykin, I. G. Nanoscale 2013, 5, 3070. http://dx.doi.org/10.1039/c3nr33513e

PMid:23463192

23. Moriyasu, T.; Sakamoto, T.; Sugihara, N.; Sasa, Y.; Ota, Y.; Shimomura, T.; Sakai, Y.; Ito, K. Polymer 2013, 54, 1490.

http://dx.doi.org/10.1016/j.polymer.2013.01.022

24. Ji, X.; Yao, Y.; Li, J.; Yan, X. Z.; Huang, F. J. Am. Chem. Soc. 2013, 135, 74.

http://dx.doi.org/10.1021/ja3108559

PMid:23259828

25. Francisco, K. R.; Dreiss, C.A.; Bouteiller, L.; Sabadini, E. Langmuir 2012, 28, 14531. $\underline{\text { http://dx.doi.org/10.1021/ja3108559 }}$

PMid:23259828

26. Vukotič, V. N.; Loeb, S. J. Chem. Soc. Rev. 2012, 41, 5896. 


\section{http://dx.doi.org/10.1039/c2cs35141b}

PMid:22717946

27. Deska, M.; Kozlowska, J.; Sliwa, W. Arkivoc 2013, (i), 294.

http://dx.doi.org/10.3998/ark.5550190.p007.774

28. Deska, M.; Kozlowska, J.; Sliwa, W. Arkivoc 2013, (i), 66.

29. Girek, B.; Sliwa, W. J. Porph. Phthal. 2013, 17, 1.

http://dx.doi.org/10.1142/S1088424612300108

30. Sliwa, W.; Bachowska, B.; Girek, T. Curr. Org. Chem. 2012, 16, 1332.

http://dx.doi.org/10.1142/S1088424612300108

31. Kozlowski, C.; Sliwa, W. Cyclodextrin polymers: recent applications; Chapter in Encyclopedia of Polymer Science and Technology; John Wiley and Sons, 2013, pp 1-14.

32. Kozlowski, C.; Nowik-Zajac, A.; Kurcok, P. Desalination and Water Treatment 2013, in press.

33. Sliwa, W.; Deska, M. Arkivoc 2012, (i), 173.

http://dx.doi.org/10.3998/ark.5550190.0013.106

34. Nowik-Zajac, A.; Kozlowski, C.A.; Trochimczuk, A. Desalination 2012, 294, 25. http://dx.doi.org/10.1016/j.desal.2012.03.003

35. Deska, M.; Sliwa, W. Covalently and noncovalently bound assemblies of calixarenes, Nova Science Publishers Inc. 2011, New York, 154 pp.

36. Trabolsi, A.; Khashab, N.; Fahrenbach, A. C.; Friedman, D. C.; Colvin, M. T.; Coti, K. K.; Benítez, D.; Tkatchouk, E.; Olsen, J-C.; Belowich, M. E.; Carmielli, R.; Khatib, H. A.; Goddard III, W. A.; Wasielewski M. R.; Stoddart, J. F. Nat. Chem. 2010, 2, 42.

http://dx.doi.org/10.1038/nchem.479

PMid:21124379

37. Hwang, I.; Ziganshina, A. Y.; Ko, Y. H.; Yun, G.; Kim, K. A. Chem. Commun. 2008, 416.

38. Li, H.; Fahrenbach, A. C.; Dey, S. K.; Basu, S.; Trabolsi, A.; Zhu, Z.; Botros, Y. Y.; Stoddart, J.F. Angew. Chem. Int. Ed. 2010, 49, 8260.

http://dx.doi.org/10.1002/anie.201004488

PMid:20865716

39. Coskun, A.; Spruell, J.M.; Barin, G.; Fahrenbach, A. C.; Forgan, R. S.; Colvin, M. T.; Carmielli, R.; Benítez, D.; Tkatchouk, E.; Friedman, D. C.; Sarjeant, A. A.; Wasielewski, M. R.; Goddard III, W. A.; Stoddart, J. F. J. Am. Chem. Soc. 2011, 133, 4538. http://dx.doi.org/10.1021/ja110584c

PMid:21366312

40. Fahrenbach, A. C.; Barnes, J. C.; Lanfranchi, D. A.; Li, H.; Coskun, A.; Gassensmith, J. J.; Liu, Z.; Benítez, D.; Trabolsi, A.; Goddard III, W. A.; Elhabiri, M.; Stoddart, J. F. J. Am. Chem. Soc. 2012, 134, 3061.

http://dx.doi.org/10.1021/ja2089603

PMid:22148229

41. Klajn, R.; Stoddart, J. F.; Grzybowski, B. A. Chem. Soc. Rev. 2010, 39, 2203. 


\section{http://dx.doi.org/10.1039/b920377j}

\section{PMid:20407689}

42. Fahrenbach, A. C.; Sampath, S.; Late, D. J.; Barnes, J. C.; Kleinman, S. L.; Valley, N.; Hartlieb, K. J.; Liu, Z.; Dravid, V. P.; Schatz, G. C.; Van Duyne, R.P.; Stoddart, J. F. ACS Nano 2012, 6, 9964.

http://dx.doi.org/10.1021/nn303553z

PMid:23078281

43. Nakahara, K.; Oyaizu, K.; Nishide, H. Chem. Lett. 2011, 40, 222.

http://dx.doi.org/10.1246/cl.2011.222

44. Usta, H.; Facchetti, A.; Marks, T. J. Acc. Chem. Res. 2011, 44. 501.

http://dx.doi.org/10.1021/ar200006r

PMid:21615105

45. Barnes, J. C.; Fahrenbach, A. C.; Dyar. S. M.; Frasconi, M.; Giesener, M. A.; Zhu, Z.; Liu, Z.; Hartlieb, K. J.; Carmieli, R.; Wasielewski, M. R.; Stoddart, J.F. PNAS 2012, 109, 11546.

http://dx.doi.org/10.1073/pnas.1201561109

PMid:22685213 PMCid:PMC3406866

46. Li, H.; Zhao, Y-L.; Fahrenbach, A. C.; Kim, S-Y.; Paxton, W. F.; Stoddart, J. F. Org. Biomol. Chem. 2011, 9, 2240.

http://dx.doi.org/10.1073/pnas.1201561109

PMid:22685213 PMCid:PMC3406866

47. Avellini, T.; Li, H.; Coskun, A.; Barin, G.; Trabolsi, A.; Basuray, A. N.; Dey, S. K.; Credi, A.; Silvi, S.; Stoddart, J. F.; Venturi, M. Angew. Chem. Int. Ed. 2012, 51, 1611. http://dx.doi.org/10.1073/pnas.1201561109

PMid:22685213 PMCid:PMC3406866

48. Zhu, Z.; Bruns, C. J.; Li, H.; Lei, J.; Ke, C.; Liu, Z.; Shafaie, S.; Colquhoun, H. M.; Stoddart, J.F. Chem. Sci. 2013, 4, 1470.

http://dx.doi.org/10.1039/c3sc00015j

49. Zhang, K-D.; Zhou, T-Y.; Zhao, X.; Jiang, X-K.; Li, Z-T.; Langmuir 2012, 28, 14839. http://dx.doi.org/10.1021/la302818r

PMid:23043416

50. Hu, J.; Zhang, G.; Liu, S. Chem. Soc. Rev. 2012, 41, 5933.

http://dx.doi.org/10.1021/la302818r

PMid:23043416

51. Aida, T.; Meijer, E. W.; Stupp, S.I.; Science 2012, 335, 813.

http://dx.doi.org/10.1126/science.1205962

PMid:22344437 PMCid:PMC3291483

52. Du, G.; Moulin, E.; Jouault, N.; Buhler, E.; Giuseppone, N. Angew. Chem. Int. Ed. 2012, 51, 12504. 
http://dx.doi.org/10.1002/anie.201206571

PMid:23081866

53. Mai, Y.; Eisenberg, A.; Chem. Soc. Rev. 2012, 41, 5969.

http://dx.doi.org/10.1039/c2cs35115c

PMid:22776960

54. Liu, Y.; Wang, Z.; Zhang, X. Chem. Soc. Rev. 2012, 41, 5922.

http://dx.doi.org/10.1039/c2cs35084j

PMid:22674180

55. Clark, J.; Lanzani, G. Nat. Photonics 2010, 4, 438.

http://dx.doi.org/10.1038/nphoton.2010.160

56. Deligkiozi, I.; Papadakis, R.; Tsolomitis, A. Supramol. Chem. 2012, 24, 333.

http://dx.doi.org/10.1080/10610278.2012.660529

57. Thibeault, D.; Morin, J-F. Molecules 2010, 15, 3709.

http://dx.doi.org/10.3390/molecules15053709

PMid:20657509

58. Semeraro, M.; Arduini, A.; Baroncini, M.; Battelli, R.; Credi, A.; Venturi, M.; Pochini, A.;

Secchi, A.; Silvi, S. Chem. Eur. J. 2010, 16, 3467.

http://dx.doi.org/10.1002/chem.200903049

PMid:20143363

59. Boccia, A.; Lanzilotto, V.; Castro V. D.; Zanoni, R.; Pescatori, L.; Arduini, A.; Secchi, A. Phys. Chem.. Chem. Phys. 2011, 13, 4452.

http://dx.doi.org/10.1039/c0cp01921f

PMid:21264385

60. Ma, X.; Sun, R.; Li, W.; Tian, H. Polym. Chem. 2011, 2, 1068.

http://dx.doi.org/10.1039/c0py00419g

61. Ogoshi, T.; Nishida, Y.; Yamagishi, T.; Nakamoto, Y. Macromolecules 2010, 43, 7068. http://dx.doi.org/10.1021/ma101320z

62. Zou, D.; Andersson, S.; Zhang, R.; Sun, S.; Åkermark, B.; Sun, L. J. Org. Chem. 2008, 73, 3775.

$\underline{\text { http://dx.doi.org/10.1021/jo800110b }}$

PMid:18419159

63. Li, C.; Xu, Q.; Li, J.; Yao,F.; Jia, X. Org. Biomol. Chem. 2010, 8, 1568.

http://dx.doi.org/10.1039/b920146g

PMid:20336850

64. Harada, A.; Hashidzume, A.; Yamaguchi, H.; Takashima, Y. Chem. Rev. 2009, 109, 5974. http://dx.doi.org/10.1021/cr9000622

PMid:19736930

65. Voskuhl, J.; Stuart, C. A.; Ravoo, B. J. Chem. Eur. J. 2010, 16, 2790.

http://dx.doi.org/10.1002/chem.200902423

PMid:20099283 
66. Müller, M. K.; Brunsveld, L. Angew. Chem. Int. Ed. 2009, 48, 2921.

http://dx.doi.org/10.1002/anie.200900143

PMid:19294717

67. Kim, S. K.; Park, K. M.; Singha, K.; Kim, J.; Ahn, Y.; Kim, K.; Kim, W. J. Chem. Commun. 2010, 46, 692.

http://dx.doi.org/10.1039/b920753h

PMid:20087489

68. Kim, J.; Ahn, Y.; Park, K. M.; Lee, D-W.; Kim, K. Chem. Eur. J. 2010, 16, 12168.

http://dx.doi.org/10.1002/chem.201001538

PMid:20859967

69. Tuncel, D.; Unal, O.; Artar, M. Israel J. Chem. 2011, 51, 525.

http://dx.doi.org/10.1002/ijch.201100034

70. Ramalingam, V.; Urbach, A. R. Org. Lett. 2011, 13, 4898.

http://dx.doi.org/10.1021/o1201991e

PMid:21846094

71. Lee, D-W.; Park, K. M.; Banerjee, M.; Ha, S. H.; Lee, T.; Suh, K.; Paul, S.; Jung, H.; Kim, J.; Selvapalam, N.; Ryu, S. H.; Kim, K. Nat. Chem. 2011, 3, 154.

http://dx.doi.org/10.1038/nchem.928

PMid:21258389

72. Nau, W. M.; Scherman, O. A. Isr. J. Chem. 2011, 51, 492.

http://dx.doi.org/10.1002/ijch.201100052

73. Kalmar, J.; Ellis, S. B.; Ashby, M. T.; Halterman, R. L. Org. Lett. 2012, 14, 3248.

http://dx.doi.org/10.1021/o1300911a

PMid:22690827

74. Gao, C.; Silvi, S.; Ma, X.; Tian, H.; Credi, A.; Venturi, M. Chem. Eur. J. 2012, 18, 16911.

$\underline{\text { http://dx.doi.org/10.1002/chem.201202378 }}$

PMid:23136090

75. Kolman, V.; Khan, M. S. A.; Babinsky, M.; Marek, R.; Sindelar, V. Org. Lett. 2011, 13, 6148.

http://dx.doi.org/10.1021/ol2023888

PMid:22066799

76. Bozdemir, O. A.; Yilmaz, M. D.; Buyukcakir, O.; Siemiarczuk, A.; Tutas, M.; Akkaya, E. U. New. J. Chem. 2010, 34, 151. http://dx.doi.org/10.1039/b9nj00380k

77. Zhao, H-X.; Guo, D-S.; Wang, L-H.; Qian, H.; Liu, Y. Chem. Commun. 2012, 48, 11319. http://dx.doi.org/10.1039/c2cc34834a

PMid:23082316

78. Ma, X.; Cao, J.; Wang, Q.; Tian, H. Chem. Commun. 2011, 47, 3559.

http://dx.doi.org/10.1039/c0cc05488g

PMid:21321705 
79. Sun, R.; Xue, C.; Ma, X.; Gao, M.; Tian, H.; Li, Q. J. Am. Chem. Soc. 2013, 135, 5990. http://dx.doi.org/10.1021/ja4016952

PMid:23574492

80. Ding, Z-J.; Zhang, H-Y.; Wang, L-H.; Ding, F.; Liu, Y. Org. Lett. 2011, 13, 856.

http://dx.doi.org/10.1021/o11028767

PMid:21268596

81. Liu, Y.; Yu, Y.; Gao, J.; Wang, Z.; Zhang, X. Angew. Chem. Int. Ed. 2010, 49, 6576.

http://dx.doi.org/10.1002/anie.201002415

PMid:20680956

82. Sun, R.; Ma, X. Tetrahedron 2013, 69, 1069.

http://dx.doi.org/10.1002/anie.201002415

PMid:20680956

83. Lindoy, L. F.; Park, K-M.; Lee, S. S. Chem. Soc. Rev. 2013, 42, 1713.

http://dx.doi.org/10.1039/c2cs35218d

PMid:22895524

84. Kato, K.; Ito, K. Reactive Functional Polymers 2013, 73, 405.

http://dx.doi.org/10.1016/j.reactfunctpolym.2012.04.021

85. Kim, D. H.; Zo, H. J.; Park, J. S. J. Appl. Polym. Sci. 2013, 127, 3864.

http://dx.doi.org/10.1002/app.37682

86. Girek, T. J. Incl. Phenom. Macrocycl. Chem. 2012, 74, 1.

http://dx.doi.org/10.1007/s10847-012-0112-1

87. Lopez-Lopez, M.; Montilla, F.; Olivares, M.; Labron, J. A.; Moya, M. L.; Lopez-Cornejo, P. Dalton Trans. 2013, 42, 6171.

http://dx.doi.org/10.1039/c3dt32197e

PMid:23525374

88. Girek, T. J. Incl. Phenom. Macrocycl. Chem. 2013, 76, 237.

http://dx.doi.org/10.1007/s10847-012-0253-2

89. Mróz, M. M.; Sforazzini, G.; Zhong, Y.; Wong, K. S.; Anderson, H. L.; Lanzani, G.; Cabanillas-Gonzalez, J. Adv. Mater. 2013, 25, 4347.

http://dx.doi.org/10.1002/adma.201301703

PMid:23813773

90. Kasiouli, S.; Di Stasio, F.; McDonnell, S.; Constantinides, C. P.; Anderson, H. L.; Cacialli, F.; Hayes, S. C. J. Phys. Chem. B. 2013, 117, 5737.

http://dx.doi.org/10.1021/jp400732h

PMid:23581599

91. Farcas, A.; Janietz, S.; Harabagiu, V.; Guegan, P.; Aubert, P-H. J. Polym. Sci. A. 2013, 51, 1672.

92. Teuchert, C.; Michel, C.; Hausen, F.; Park, D-Y.; Beckham, H. W.; Wenz, G. Macromolecules 2013, 46, 2.

http://dx.doi.org/10.1021/ma302204a 
93. Jiang, L.; Gao, Z-M.; Ye, L.; Zhang, A-Y.; Feng, Z-G. Polymer 2013, 54, 5188. http://dx.doi.org/10.1016/j.polymer.2013.07.044

94. Sabadini, E.; do Carmo, E.F.; Cosgrove, T. Langmuir 2013, 29, 4664. http://dx.doi.org/10.1021/la304910v

PMid:23510502

95. Tang, C.; Inomata, A.; Sakai, Y.; Yokoyama, H.; Miyoshi, T.; Ito, K. Macromolecules 2013, 46, 6898.

http://dx.doi.org/10.1021/ma401476g

96. Wang, G-W. Chem. Soc. Rev. 2013, 42, 7668.

http://dx.doi.org/10.1039/c3cs35526h

PMid:23660585

97. Boccia, A.; D’Orazi, F.; Carabelli, E.; Bussolati, R.; Arduini, A.; Secchi, A.; Marrani, A. G.; Zanoni, R. Chem. Eur. J. 2013, 19, 7999.

http://dx.doi.org/10.1002/chem.201204318

PMid:23606638

98. Talotta, C.; Gaeta, C.; Qi, Z.; Schalley, C. A.; Neri, P. Angew. Chem. Int. Ed. 2013, 52, 7437.

http://dx.doi.org/10.1002/anie.201301570

PMid:23740624

99. Arduini, A.; Bussolati, R.; Credi, A.; Secchi, A.; Silvi, S.; Semeraro, M.; Venturi, M. J. Am. Chem. Soc. 2013, 135, 9924.

http://dx.doi.org/10.1021/ja404270c

PMid:23751139

100. Green, D. P.; Jain, V.; Bailey, B. Wagner, M.; Clark, M.; Valeri, D.; Lakso, S. Proceedings of SPIE 2013, Part 1, 8679.

101. Ward, J. P.; White, J. M.; Young, C. G. Tetrahedron 2013, 69, 8824.

http://dx.doi.org/10.1016/j.tet.2013.05.120

102. Gramage-Doria, R.; Armspach, D.; Matt, D. Coord. Chem. Revs. 2013, 257, 776.

http://dx.doi.org/10.1016/j.ccr.2012.10.006

103. Zawierucha, I.; Kozlowski, C.; Malina, G. Waste Management 2013, 33, 2129.

http://dx.doi.org/10.1016/j.wasman.2012.12.015

PMid:23312781

104. Li, N.; Yang, F.; Stock, H. A.; Dearden, D. V.; Lamb, J. D.; Harrison, R. G. Org. Biomol. Chem. 2012, 10, 7392.

http://dx.doi.org/10.1039/c2ob25613d

PMid:22865201

105. Tiefenbacher, K.; Rebek Jr., J. J. Am. Chem. Soc. 2012, 134, 2914.

http://dx.doi.org/10.1021/ja211410x

PMid:22263583

106. Yamanaka, M.; Kobayashi, K. Asian J. Org. Chem. 2013, 2, 276. 
107. Taira, T.; Ajami, D.; Rebek Jr., J. J. Am. Chem. Soc. 2012, 134, 11971. http://dx.doi.org/10.1021/ja304556c

PMid:22765643

108. Da Silva, J.P.; Kulasekharan, R.; Cordeiro, C.; Jockusch, S.; Turro, N.J.; Ramamurthy, V. Org. Lett. 2012, 14, 560.

http://dx.doi.org/10.1021/ol203139v

PMid:22195767

109. Boinski, T.; Szumna, A. Tetrahedron 2012, 68, 9419; Erratum Tetrahedron 2013, 69, 957. http://dx.doi.org/10.1016/j.tet.2012.11.044

110. Yu, G.; Xue, M.; Zhang, Z.; Li, J.; Han, C.; Huang, F. J. Am. Chem. Soc 2012, 134, 13248. http://dx.doi.org/10.1021/ja306399f

PMid:22827832

111. Zhang, Z.; Luo, Y.; Xia, B.; Han, C.; Yu, Y.; Chen, X.; Huang, F. Chem. Commun. 2011, 47, 2417.

http://dx.doi.org/10.1039/c0cc03732j

PMid:21173951

112. Kudo, H.; Niina, N.; Hayashi, R.; Kojima, K.; Nishikubo, T. Macromolecules 2010, 43, 4822 . http://dx.doi.org/10.1021/ma100527f

113. Saito, Y.; Saito, R.; Kudo, H.; Nishikubo, T. Macromolecules 2008, 41, 3755. http://dx.doi.org/10.1021/ma800287j

114. Gao, L.; Han, C.; Zheng, B.; Dong, S.; Huang, F. Chem. Commun. 2013, 49, 472. http://dx.doi.org/10.1039/c2cc37646f PMid:23201975

115. Ogoshi, T.; Nishida, Y.; Yamagishi T-A.; Nakamoto, Y. Macromolecules 2010, 43, 3145. http://dx.doi.org/10.1021/ma100079g

116. Yang, H.; Ma, Q.; Tan, Y. J. Polym. Res. 2013, 20, 1.

117. Gamal-Eldin, M.A.; Macartney, D.H. Org. Biomol. Chem. 2013, 11, 1234. http://dx.doi.org/10.1039/c2ob27282b

PMid:23314170

118. Yi, J-M.; Ni, X-L.; Xiao, X.; Lu, L-B.; Xue, S-F.; Zhu, Q-J.; Tao, Z. Chinese Chem. Lett. 2013, 24, 362. http://dx.doi.org/10.1016/j.cclet.2013.03.023

119. Ke, C.; Smaldone, R.A.; Kikuchi, T.; Li, H.; Davis, A.P.; Stoddart, J.F. Angew. Chem. Int. Ed. 2013, 52, 381. http://dx.doi.org/10.1002/anie.201205087

PMid:22976927

120. Li, L.; Zhang, H-Y.; Zhao, J.; Li, N.; Liu, Y. Chem. Eur. J. 2013, 19, 6498. http://dx.doi.org/10.1002/chem.201204583

PMid:23505011 


\section{Authors' Biographies}

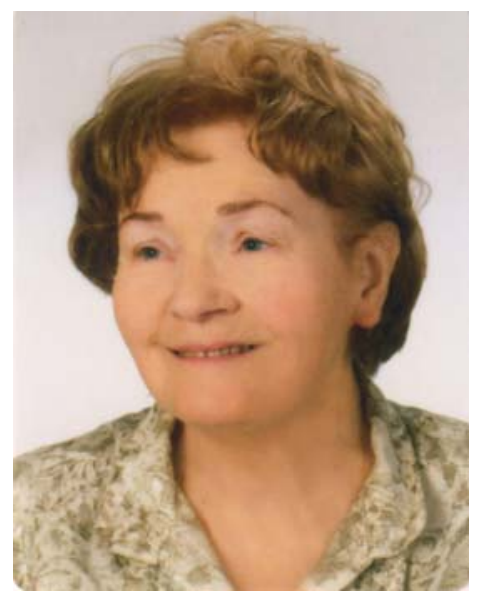

Wanda Sliwa graduated from Wrocław University of Technology, Poland where she became an associate professor. After a year research at Université Paul Sabatier a Toulouse, France, she moved to Jan Dlugosz University of Czestochowa, Poland, where she has been Professor of Chemistry since 1990, as well as being a vice-rector, head of the Organic Chemistry Department and director of the Institute of Chemistry. She is author or coauthor of four books and 16 monographs, around 350 papers and ten patents, and has received several awards for scientific and pedagogical achievements. Her research concerns azaaromatic compounds and supramolecular chemistry.

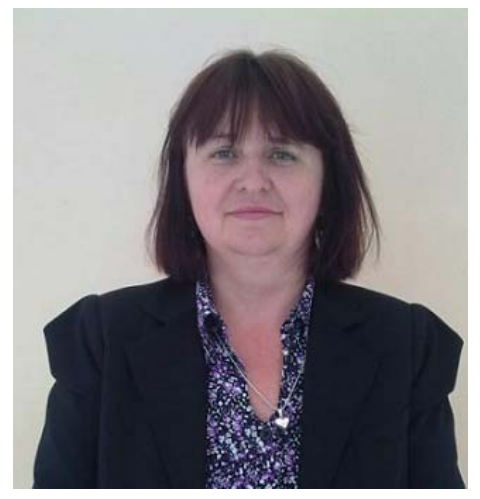

Malgorzata Deska graduated from Pedagogical University of Częstochowa, Poland, she received there M.Sc. degree in 1990. Since this time she works at Jan Długosz University (formerly Pedagogical University) of Częstochowa in Organic Chemistry Department and in Biochemistry Department. In 2004 she obtained her PhD at Technical University of Cracow, the doctor thesis concerned physicochemical properties of diazaphenanthrenes. She has published 17 papers in refereed journals, 7 communications to scientific meetings and is a coauthor of a book. The research interests of Dr Malgorzata Deska are connected with chemistry of heterocyclic compounds, cyclodextrins and calixarenes. 


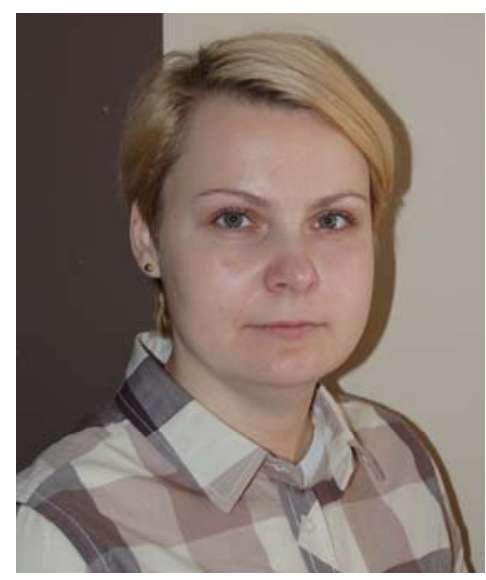

Anna Nowik-Zajac graduated from Nicolaus Copernicus University of Torun, Poland and received there the Biotechnology M.Sc degree in 2007. Since this time she works at Jan Dlugosz University of Czestochowa, in Institute of Chemistry, Environmental Protection and Biotechnology. She is coauthor of 7 papers in refereed journals, and of 6 conference communications. Her research is connected with application of membrane technics in separation of metal ions. 